University of Nebraska - Lincoln

DigitalCommons@University of Nebraska - Lincoln

\title{
Incorporating a completely renormalized coupled cluster approach into a composite method for thermodynamic properties and reaction paths
}

\author{
Sean A. Nedd \\ lowa State University, snedd@chem.ucla.edu \\ Nathan J. DeYonker \\ The University of Memphis, ndyonker@memphis.edu \\ Angela K. Wilson \\ University of North Texas, akwilson@unt.edu \\ Mark S. Gordon \\ lowa State University, mark@si.msg.chem.iastate.edu \\ Piotr Piecuch \\ Michigan State University, piecuch@chemistry.msu.edu
}

Follow this and additional works at: https://digitalcommons.unl.edu/usdoepub

Part of the Bioresource and Agricultural Engineering Commons

Nedd, Sean A.; DeYonker, Nathan J.; Wilson, Angela K.; Gordon, Mark S.; and Piecuch, Piotr, "Incorporating a completely renormalized coupled cluster approach into a composite method for thermodynamic properties and reaction paths" (2012). US Department of Energy Publications. 341.

https://digitalcommons.unl.edu/usdoepub/341

This Article is brought to you for free and open access by the U.S. Department of Energy at DigitalCommons@University of Nebraska - Lincoln. It has been accepted for inclusion in US Department of Energy Publications by an authorized administrator of DigitalCommons@University of Nebraska - Lincoln. 


\title{
Incorporating a completely renormalized coupled cluster approach into a composite method for thermodynamic properties and reaction paths
}

\author{
Sean A. Nedd, ${ }^{1}$ Nathan J. DeYonker, ${ }^{2}$ Angela K. Wilson, ${ }^{3}$ Piotr Piecuch, ${ }^{4}$ \\ and Mark S. Gordon ${ }^{1, a)}$ \\ ${ }^{1}$ Ames Laboratory, US DOE and Department of Chemistry, Iowa State University, Ames, Iowa 50011, USA \\ ${ }^{2}$ Department of Chemistry, The University of Memphis, Memphis, Tennessee 38152, USA \\ ${ }^{3}$ Department of Chemistry and Center for Advanced Scientific Computing and Modeling (CASCaM), \\ University of North Texas, Denton, Texas 76203-5017, USA \\ ${ }^{4}$ Department of Chemistry, Michigan State University, East Lansing, Michigan 48824, USA
}

(Received 24 January 2012; accepted 20 March 2012; published online 12 April 2012)

\begin{abstract}
The correlation consistent composite approach (ccCA), using the $\mathrm{S} 4$ complete basis set two-point extrapolation scheme (ccCA-S4), has been modified to incorporate the left-eigenstate completely renormalized coupled cluster method, including singles, doubles, and non-iterative triples (CR-CC $(2,3)$ ) as the highest level component. The new ccCA-CC $(2,3)$ method predicts thermodynamic properties with an accuracy that is similar to that of the original ccCA-S4 method. At the same time, the inclusion of the single-reference $\mathrm{CR}-\mathrm{CC}(2,3)$ approach provides a ccCA scheme that can correctly treat reaction pathways that contain certain classes of multi-reference species such as diradicals, which would normally need to be treated by more computationally demanding multi-reference methods. The new ccCA-CC $(2,3)$ method produces a mean absolute deviation of $1.7 \mathrm{kcal} / \mathrm{mol}$ for predicted heats of formation at $298 \mathrm{~K}$, based on calibration with the G2/97 set of 148 molecules, which is comparable to that of $1.0 \mathrm{kcal} / \mathrm{mol}$ obtained using the ccCA-S4 method, while significantly improving the performance of the ccCA-S4 approach in calculations involving more demanding radical and diradical species. Both the ccCA-CC $(2,3)$ and ccCA-S4 composite methods are used to characterize the conrotatory and disrotatory isomerization pathways of bicyclo[1.1.0]butane to trans-1,3-butadiene, for which conventional coupled cluster methods, such as the $\operatorname{CCSD}(\mathrm{T})$ approach used in the ccCA-S4 model and, in consequence, the ccCA-S4 method itself might fail by incorrectly placing the disrotatory pathway below the conrotatory one. The $\operatorname{ccCA}-\mathrm{CC}(2,3)$ scheme provides correct pathway ordering while providing an accurate description of the activation and reaction energies characterizing the lowest-energy conrotatory pathway. The ccCA-CC $(2,3)$ method is thus a viable method for the analyses of reaction mechanisms that have significant multi-reference character, and presents a generally less computationally intensive alternative to true multi-reference methods, with computer costs and ease of use that are similar to those that characterize the more established, CCSD(T)-based, ccCA-S4 methodology. (O) 2012 American Institute of Physics. [http://dx.doi.org/10.1063/1.3700801]
\end{abstract}

\section{INTRODUCTION}

Composite electronic structure methods employ several levels of theory in a single series of calculations to predict equilibrium properties of molecules, and they are frequently used to provide thermodynamic properties within chemical accuracy $( \pm 1.0 \mathrm{kcal} / \mathrm{mol})$ at a modest computational cost. Composite methods can achieve a relatively low computational cost by taking advantage of the near additivity of improvements in the level of theory and of the atomic basis set. ${ }^{1-3}$ Among the composite methods that take advantage of this additivity are the Gaussian (Gn) methods (G1, G2, G3, G4, G3(MP2), and G4(MP2)), ${ }^{4-7}$ the Weizmann (Wn) methods (W1, W2, W3, W4), ${ }^{8-10}$ the Bond Additivity Correction (BAC) methods (BAC-G2, G3B3, G3MP2B3), ${ }^{11,12}$ the complete basis set (CBS) method developed by Petersson and co-workers, ${ }^{13-17}$ the ab initio thermochemical method by

\footnotetext{
a) Author to whom correspondence should be addressed. Electronic mail: mark@si.msg.chem.iastate.edu.
}

Stanton and co-workers, ${ }^{18-20}$ the Feller-Peterson-Dixon (FPD) composite method, ${ }^{21-26}$ the multicoefficient correlation method by Truhlar and co-workers, ${ }^{27-30}$ and the correlation consistent composite approach (ccCA) methods (cc-CA-S3, ccCA-P, ccCA-S4). ${ }^{31-34}$ DeYonker et al. ${ }^{31}$ have shown that the ccCA method delivers improvements over the more commonly used Gn and Wn series of methods, since the ccCA method does not use empirical parameters, in contrast to the Gn methods and is less computationally demanding than the Wn methods. The Gn methods introduce higher-level corrections (HLCs), fitted parameters that are functions of the number of alpha and beta electrons in the system of interest. The total energy corrections from the HLCs can cause a deterioration in the accuracy of the calculated final energies since the magnitude of the HLC corrections increases with system size. ${ }^{4}$ The Wn methods include coupled cluster (CC) levels as high as five-particle cluster operators (CCSDTQ5), making the methods computationally very intensive and therefore difficult to apply to molecules with more than a small number of atoms. The ccCA method makes use of correlation 
consistent basis sets ${ }^{35-38}$ that converge systematically to the CBS limit by using an extrapolation scheme. ${ }^{31}$ The ccCA method is computationally more efficient than the Wn methods, since the highest level of theory employed for the ccCAS4 (Ref. 31) method is coupled cluster with singles, doubles, and perturbative triples $\left(\operatorname{CCSD}(\mathrm{T})^{39}\right)$.

In the ccCA-S4 method, energy corrections account for Douglas-Kroll scalar relativistic effects, core-valence corrections, and CBS two-point extrapolation. ${ }^{31}$ The ccCA-S4 method will be discussed in more detail below.

The composite methods mentioned above are all based on single-reference (SR) levels of theory. There are some composite methods that explicitly include multi-reference (MR) levels of theory, including the MR versions of the Gn methods, ${ }^{40}$ the MR W1CAS and W2CAS methods, ${ }^{41}$ and the MR-ccCA methods..$^{42-44}$ A disadvantage of using explicitly MR methods is that active spaces can be difficult to choose, and MR methods based on the complete-active-space reference spaces scale exponentially with the size of the system.

The left eigenstate completely renormalized coupled cluster singles, doubles and non-iterative triples (CR$\mathrm{CC}(2,3))$ approach has been shown to accurately treat single bond breaking and bond formation, as well as chemical reaction profiles involving closed-shell, radical, and diradical species at a computational cost similar to that of $\operatorname{CCSD}(\mathrm{T}){ }^{45,46}$ Therefore, the SR CR-CC $(2,3)$ method can account for the MR nature of many chemically important systems and can also potentially be incorporated into a composite method to provide accurate treatments of chemical reaction profiles and at least some diradical species. In this paper, both experimental results and the original ccCA-S4 method are employed as calibrations to assess the CR-CC $(2,3)$-based modification of the method. The new ccCA-CC $(2,3)$ method has been implemented in the GAMESS (general atomic and molecular electronic structure system $)^{48}$ computational package, using the spin-free, RHF-based CR-CC $(2,3)$ routines for closed shells described in Ref. 45 and the spin-integrated, ROHF-based CR-CC $(2,3)$ routines for open shells described in Ref. 46. A spin-restricted RHF/ROHF-based ccCA-S4 method, in which the closed-shell calculations are performed with the help of the spin-free $\operatorname{CCSD}(\mathrm{T})$ routines described in Ref. 47 and in which the open-shell calculations rely on the ROHF-based CR-CC $(2,3)$ codes,${ }^{46}$ has also been implemented in GAMESS. The aim of the ccCA-CC $(2,3)$ method is to provide thermodynamic properties for closed-shell species and diradicals, as well as for open-shell systems, with an accuracy that is close to the chemical accuracy $( \pm 1.0 \mathrm{kcal} / \mathrm{mol}$ mean absolute deviation) provided by the ccCA-S4 method, if systems under consideration do not include diradical and other MR species. The ccCA-S4 and ccCA-CC $(2,3)$ methods are compared using the G2/97 set of 148 molecules, ${ }^{5,49}$ and by examining the thermal pericyclic rearrangement of bicyclo[1.1.0]butane (bicbut) to trans-buta-1,3-diene, which contains a disrotatory transition state that is a diradical species. The isomerization of bicyclo[1.1.0]butane (bicbut) to transbuta-1,3-diene presents a good test for the viability of the ccCA-CC $(2,3)$ method, since it is generally difficult to obtain a highly accurate description of the experimentally accessible conrotatory pathway that characterizes this rearrange- ment reaction, while the higher energy disrotatory pathway is poorly described by conventional SR approaches, such as $\operatorname{CCSD}(\mathrm{T}) .{ }^{50} \mathrm{~A}$ viable composite method should predict that the conrotatory transition state is favored, and the ability of the ccCA-CC $(2,3)$ approach to do this is examined in the present study.

In the present work, the following ccCA calculations are presented:

(1) The GAMESS RHF-/ROHF-based ccCA-S4 (GROS4) method, in which closed-shell calculations use $\operatorname{CCSD}(\mathrm{T})$ and open-shell calculations use CR-CC(2,3), is compared with unpublished RHF-/ROHF-based ccCA-S4 (uROS4) data, employing CCSD(T) for closed and open shells, and experimental heats of formation for the $\mathrm{G} 2 / 97$ set.

(2) The ccCA-CC $(2,3)$ method, also abbreviated as GROS4$\mathrm{CC}(2,3)$, is calibrated against the uROS4 and experimental heats of formation data.

(3) The ccCA-S4 and ccCA-CC $(2,3)$ methods are compared for the structures and relative energies along the thermal pericyclic rearrangement reaction pathways.

The heats of formation results from the calibrations among GROS4, GROS4-CC(2,3), and uROS4 are expected to be similar for each species. However, mean absolute deviation (MAD) values will determine the ultimate accuracy for each ccCA calculation of GROS4, GROS4-CC $(2,3)$, uROS4, and also experimental values.

\section{THEORY AND COMPUTATIONAL DETAILS}

\section{A. Description of ccCA theories}

\section{1. ccCA-S4 method}

The ccCA-S4 (Refs. 31 and 32) method makes use of second-order Møller-Plesset perturbation theory (MP2), ${ }^{51}$ density functional theory (DFT) using the B3LYP functional, ${ }^{52}$ and $\operatorname{CCSD}(\mathrm{T}){ }^{39}$ The notation "E(A/B)" indicates an energy calculation using method " $\mathrm{A}$ " with the basis set "B." The basis sets used in the method are primarily the correlation consistent cc-pVXZ ${ }^{36,38}$ and aug-cc-pVXZ ${ }^{53,54}$ basis sets. The 6-31G(2df,p) Pople basis set ${ }^{55}$ is used for geometry optimizations. ${ }^{31,32}$ Scalar relativistic effects are accounted for with the second-order Douglas-Kroll-Hess (DK)derived correlation consistent basis sets, cc-pVXZ-DK; ${ }^{56-58}$ core valence $(\mathrm{CV})$ correlation effects are included using the aug-cc-pCVXZ ${ }^{53,54,59}$ basis sets.

Energy and structure optimizations, and semi-numerical (finite differencing of analytic first derivatives) Hessian calculations are prepared using B3LYP/6-31G $(2 d f, p)$ with Cartesian Gaussian functions $(6 d, 10 f) \cdot{ }^{60,61}$ All other calculations are single point energy calculations which make use of spherical Gaussian functions $(5 d, 7 f)$. The following shorthand notation is used:

$\mathrm{AVXZ}=$ aug-cc-pVXZ;

VTZ-DK $=$ cc-pVTZ-DK (no tight $d$ functions);

$\mathrm{NVTZ}=\mathrm{cc}-\mathrm{pVTZ}$ (no tight $d$ functions); 
$\mathrm{VTZ}=\mathrm{cc}-\mathrm{pVTZ}$ (tight $d$ functions on Al-Ar atoms); $\mathrm{ACVTZ}=$ aug-cc-pCVTZ.

The final ccCA-S4 energy at $0 \mathrm{~K}(\mathrm{E}(\mathrm{ccCA}-\mathrm{S} 4))$ is

$$
\begin{aligned}
\mathrm{E}(\mathrm{ccCA}-\mathrm{S} 4)= & \mathrm{E}(\mathrm{MP} 2 / \mathrm{CBS})+\Delta \mathrm{E}(\mathrm{SR}-\mathrm{MP} 2) \\
& +\Delta \mathrm{E}(\mathrm{CC})+\Delta \mathrm{E}(\mathrm{CV})+\mathrm{ZPE} .
\end{aligned}
$$

In Eq. (1), $\Delta \mathrm{E}(\mathrm{SR}-\mathrm{MP} 2), \Delta \mathrm{E}(\mathrm{CC})$, and $\Delta \mathrm{E}(\mathrm{CV})$ are, respectively, the corrections (assumed to be additive) for Douglas-Kroll, the coupled cluster contributions beyond MP2, and the core and core-valence correlation effects. ZPE refers to the scaled $(0.9854)$ zero point vibrational energy correction. ${ }^{55}$

The ccCA-S4 energy at $298 \mathrm{~K}(\mathrm{E}(\mathrm{ccCA}-\mathrm{S} 4,298 \mathrm{~K}))$ is

$$
\mathrm{E}(\mathrm{ccCA}-\mathrm{S} 4,298 \mathrm{~K})=\mathrm{E}(\mathrm{ccCA}-\mathrm{S} 4)+\mathrm{ETH} .
$$

In Eq. (2), ETH represents the thermal energy correction at $298 \mathrm{~K}$. The scaled ZPE and ETH thermodynamic energy term values are obtained from the GAMESS Hessian calculation.

$\mathrm{E}(\mathrm{MP} 2 / \mathrm{CBS})$ is the energy resulting from the twopoint complete basis set extrapolation of $\mathrm{E}(\mathrm{MP} 2 / \mathrm{AVQZ})$ and $\mathrm{E}(\mathrm{MP} 2 / \mathrm{AVTZ})$ based on the equation ${ }^{32}$

$$
\mathrm{E}\left(l_{\max }\right)=\mathrm{E}(\mathrm{MP} 2 / \mathrm{CBS})+\frac{\mathrm{B}}{\left(l_{\max }+\frac{1}{2}\right)^{4}},
$$

where $l_{\max }$ is the highest angular momentum in the basis set and $\mathrm{B}$ is a constant. For E(MP2/AVTZ), $l_{\max }$ is 3 and for $\mathrm{E}(\mathrm{MP} 2 / \mathrm{AVQZ}), l_{\max }$ is 4 ; total energies are used. Using Eq. (3) and the $l_{\max }$ value for $\mathrm{E}(\mathrm{MP} 2 / \mathrm{AVTZ})$,

$$
\mathrm{E}(\mathrm{MP} 2 / \mathrm{AVTZ})=\mathrm{E}(3)=\mathrm{E}(\mathrm{MP} 2 / \mathrm{CBS})+\frac{2^{4} \times \mathrm{B}}{7^{4}},
$$

and for $\mathrm{E}(\mathrm{MP} 2 / \mathrm{AVQZ})$,

$$
\mathrm{E}(\mathrm{MP} 2 / \mathrm{AVQZ})=\mathrm{E}(4)=\mathrm{E}(\mathrm{MP} 2 / \mathrm{CBS})+\frac{2^{4} \times \mathrm{B}}{9^{4}} .
$$

After rearranging Eqs. (4) and (5) to solve for $\mathrm{E}(\mathrm{MP} 2 / \mathrm{CBS})$, one obtains

$$
\begin{aligned}
\mathrm{E}(\mathrm{MP} 2 / \mathrm{CBS})= & \left(\frac{6561}{4160}\right) \times \mathrm{E}(\mathrm{MP} 2 / \mathrm{AVQZ}) \\
& -\left(\frac{2401}{4160}\right) \times \mathrm{E}(\mathrm{MP} 2 / \mathrm{AVTZ}) .
\end{aligned}
$$

The ccCA-S4 molecular energy values from Eqs. (1) and (2) are used to obtain heats of formation values. The following standard shorthand notation is used for all heats of formation calculations:

$\Delta \mathrm{H}_{f 0}=$ ccCA heats of formation at $0 \mathrm{~K}$;

$\Delta \mathrm{H}_{f 298}=\mathrm{ccCA}$ heats of formation at $298 \mathrm{~K}$;

$\mathrm{E}_{\mathrm{tot} 0}=$ sum of atom ccCA total energies at $0 \mathrm{~K}$;

$\mathrm{E}_{\mathrm{tot} 298}=$ sum of atom ccCA total energies at $298 \mathrm{~K}$;
$\Delta \mathrm{H}_{a 0}=$ sum of heats of atomization ${ }^{62-64}$ at $0 \mathrm{~K}$;

$\Delta \mathrm{H}_{a 298}=$ sum of heats of atomization ${ }^{62-64}$ at $298 \mathrm{~K}$.

The $\Delta \mathrm{H}_{f 0}$ and $\Delta \mathrm{H}_{f 298}$ for ccCA-S4 are expressed as

$$
\begin{gathered}
\Delta \mathrm{H}_{f 0}=\mathrm{E}(\mathrm{ccCA}-\mathrm{S} 4)-\mathrm{E}_{\mathrm{tot} 0}+\Delta \mathrm{H}_{a 0}, \\
\Delta \mathrm{H}_{f 298}=\mathrm{E}(\mathrm{ccCA}-\mathrm{S} 4)-\mathrm{E}_{\mathrm{tot} 298}+\Delta \mathrm{H}_{a 298} .
\end{gathered}
$$

\section{2. $c c C A-C C(2,3)$ method}

This composite method follows the ccCA-S4 approach described above, but replaces $\mathrm{CCSD}(\mathrm{T})$ by $\mathrm{CR}-\mathrm{CC}(2,3)$. The final ccCA-CC $(2,3)$ energy at $0 \mathrm{~K}(\mathrm{E}(\operatorname{ccCA}-\mathrm{CC}(2,3)))$ is

$$
\begin{aligned}
\mathrm{E}(\mathrm{ccCA}-\mathrm{CC}(2,3))= & \mathrm{E}(\mathrm{MP} 2 / \mathrm{CBS})+\Delta \mathrm{E}(\mathrm{SR}-\mathrm{MP} 2) \\
& +\Delta \mathrm{E}(\mathrm{CC})+\Delta \mathrm{E}(\mathrm{CV})+\mathrm{ZPE}, \quad(9)
\end{aligned}
$$

and the final ccCA-CC $(2,3)$ energy at $298 \mathrm{~K}$ (E(ccCA$\mathrm{CC}(2,3) 298 \mathrm{~K}))$ is

$\mathrm{E}(\operatorname{ccCA}-\mathrm{CC}(2,3) 298 \mathrm{~K})=\mathrm{E}(\operatorname{ccCA}-\mathrm{CC}(2,3))+\mathrm{ETH}$,

where $\triangle \mathrm{E}(\mathrm{CC})$ now represents the $\mathrm{CR}-\mathrm{CC}(2,3)$ energy correction beyond MP2 and is

$$
\Delta \mathrm{E}(\mathrm{CC})=\mathrm{E}(\mathrm{CR}-\mathrm{CC}(2,3) / \mathrm{VTZ})-\mathrm{E}(\mathrm{MP} 2 / \mathrm{VTZ}) .
$$

The ccCA-CC $(2,3)$ heats of formation are calculated in the same way as for the ccCA-S4,

$$
\Delta \mathrm{H}_{f 0}=\mathrm{E}(\mathrm{ccCA}-\mathrm{CC}(2,3))-\mathrm{E}_{\mathrm{tot} 0}+\Delta \mathrm{H}_{a 0},
$$

and $\Delta H_{f 298}$ for ccCA-CC $(2,3)$ is

$$
\Delta \mathrm{H}_{f 298}=\mathrm{E}(\mathrm{ccCA}-\mathrm{CC}(2,3))-\mathrm{E}_{\mathrm{tot} 298}+\Delta \mathrm{H}_{a 298} .
$$

The calibration comparisons, presented in the following paragraphs, compare the GAMESS RHF-/ROHF-based ccCAS4 (GROS4) and ccCA-CC $(2,3)$ predictions, where GROS4 uses RHF-based $\operatorname{CCSD}(\mathrm{T})$ for closed shells and ROHF-based CR-CC $(2,3)$ for open shells and ccCA-CC $(2,3)$ employs the restricted $\mathrm{CR}-\mathrm{CC}(2,3)$ approach for both closed and open shells, with those from the unpublished RHF-/ROHF-based ccCA-S4 (uROS4) calculations, in which $\operatorname{CCSD}(\mathrm{T})$ is utilized throughout, and experimental heats of formation. These comparisons employ the $298 \mathrm{~K}$ heats of formation from the ccCA-S4 and ccCA-CC $(2,3)$ methods. The ccCA-S4 and ccCA-CC $(2,3)$ methods are also used to obtain the relative energies of structures along the thermal pericyclic rearrangement reaction pathway described below.

\section{B. Thermal pericyclic rearrangement calculations}

The thermal pericyclic rearrangement follows two pathways: a disrotatory pathway and a conrotatory pathway. Each of the pathways, as shown in Figure 1, contains five species, four of which are the same for both pathways. The one species that differs is the initial transition state structure. The initial transition state is either of the conrotatory type (for a conrotatory pathway) or of the disrotatory type (for a disrotatory pathway). These pericyclic rearrangement pathways are parts of 


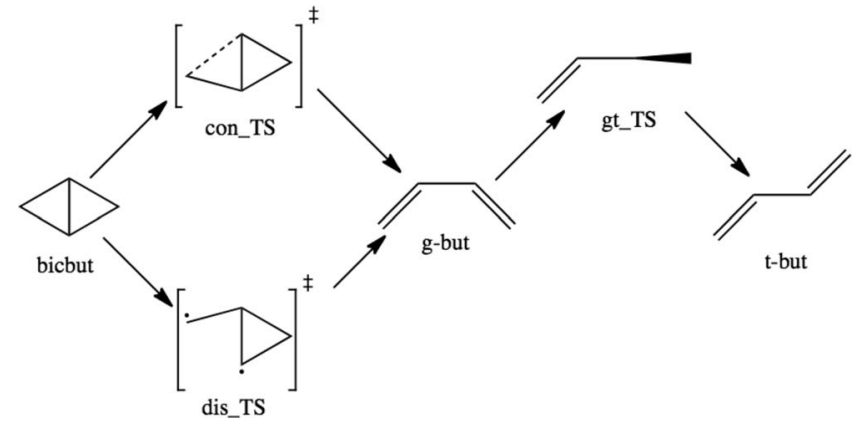

FIG. 1. Pathways in the thermal pericyclic rearrangement (see text for description).

concerted mechanisms in which the conrotatory pathway appears to be favored. ${ }^{50,65-70}$ All six species in the two reaction paths are illustrated in Figure 1, with the following shorthand notation in parentheses: bicyclo[1.1.0]butane (bicbut) reactant, two transition states (disrotatory transition state (dis_TS) and conrotatory transition state (con_TS)), gauche-buta-1,3diene (g-but) local minimum, gauche transition state (gt_TS), and trans-buta-1,3-diene final product (t-but).

The energies of all six structures were determined using the ccCA-S4 and ccCA-CC(2,3) methods implemented in GAMESS, as described above. Structures for each of the species in the pericyclic rearrangement, as well as the corresponding zero-point vibrational energies, were taken from supporting material provided in a previous paper. ${ }^{50}$ These structures and zero-point energies were obtained using the complete active space self-consistent field (CASSCF) approach, ${ }^{71,72}$ employing 10 active orbitals and 10 active electrons, and referred to as $\operatorname{CASSCF}(10,10)$. These CASSCF $(10,10)$-based geometries replace the prescribed B3LYP/6-31G(2df,p)-based geometries in the ccCA-S4 and ccCA-CC $(2,3)$ methods, since it is established in Ref. 50 that B3LYP-based geometries are insufficient for describing the pericyclic rearrangement.

\section{RESULTS AND DISCUSSION}

\section{A. ccCA-S4 and ccCA-CC(2,3) calibration and comparisons}

Tables I-IV list $298 \mathrm{~K}$ heats of formation for the ccCAS4 and ccCA-CC $(2,3)$ methods and compare their values with those obtained from experiment (expt.), as well as unpublished RHF-/ROHF-based ccCA-S4 (uROS4) results. The mean absolute deviations are included in these tables.

In Table I, for the G2-1 set (the first 55 species of the $\mathrm{G} 2 / 97$ set) the MAD between ccCA-S4 in GAMESS (GROS4) and experiment is $0.8 \mathrm{kcal} / \mathrm{mol}$; that between GROS4 and uROS4 is $0.5 \mathrm{kcal} / \mathrm{mol}$; and that between uROS4 and experiment is $0.8 \mathrm{kcal} / \mathrm{mol}$. So, for the $\mathrm{G} 2-1 \mathrm{set}$, the ccCA-S4 method is consistent with uROS4 data. In general, a measure of good chemical accuracy is a MAD value less than $1.0 \mathrm{kcal} / \mathrm{mol}$. Since the CR-CC $(2,3)$ coupled cluster method is used as a substitute for $\operatorname{CCSD}(\mathrm{T})$ in the GROS4 implementation of ccCA-S4 for open-shell species, the agreement between GROS4 and its uROS4 counterpart which relies on
CCSD(T) for both closed and open shells shown in Table I is encouraging. In order to directly compare CCSD(T)-based results, the singlet species MAD values for the G2-1 set are also presented in Table I. For the ccCA-S4 method, the G2-1 singlet species MAD between GROS4 and experiment is $0.6 \mathrm{kcal} / \mathrm{mol}$; that between GROS4 and uROS4 is $0.4 \mathrm{kcal} / \mathrm{mol}$; and that between uROS4 and experiment is $0.8 \mathrm{kcal} / \mathrm{mol}$. These MAD values for the $\mathrm{G} 2-1$ singlet species indicate that the GROS4 method does provide heats of formation that are within chemical accuracy, overall.

Table II contains a similar comparison to Table I for the G2-2 set, which represents the remaining 97 species in the full G2 set. For ccCA-S4, the MAD value for the G22 set between GROS4 and experiment is $1.1 \mathrm{kcal} / \mathrm{mol}$; that between GROS4 and uROS4 is $0.8 \mathrm{kcal} / \mathrm{mol}$; and that between uROS4 and experiment is $0.8 \mathrm{kcal} / \mathrm{mol}$. The higher MAD values are a reflection of larger errors in the both the singlets and non-singlets in the G2-2 set. For example, the MAD values between GROS4 and experiment for just the G22 singlet species is $1.1 \mathrm{kcal} / \mathrm{mol}$, an increase of $0.5 \mathrm{kcal} / \mathrm{mol}$ relative to the G2-1 set, while the MAD value for the G22 non-singlet species is $1.5 \mathrm{kcal} / \mathrm{mol}$. Overall, for the entire G2/97 set (G2-1 + G2-2) the MAD between GROS4 and experiment is $1.0 \mathrm{kcal} / \mathrm{mol}$; that between GROS4 and uROS4 is $0.7 \mathrm{kcal} / \mathrm{mol}$; and that between uROS4 and experiment is $0.8 \mathrm{kcal} / \mathrm{mol}$, all within chemical accuracy. For ccCA-S4, the small changes in MAD errors between GROS4 and uROS4 for all $\mathrm{G} 2 / 97$ species $(0.2 \mathrm{kcal} / \mathrm{mol})$ and for only the $\mathrm{G} 2 / 97$ singlet species $(0.1 \mathrm{kcal} / \mathrm{mol})$ indicate that using the ROHFbased CR-CC $(2,3)$ approach is an acceptable substitution for using the ROCCSD(T) method. The maximum (MAX) error between GROS4 and experiment for all species in the G2/97 set is $4.6 \mathrm{kcal} / \mathrm{mol}$, which is only $0.4 \mathrm{kcal} / \mathrm{mol}$ greater than the corresponding MAX error between uROS4 and experiment. The MAX error between GROS4 and uROS4 for all species in the G2/97 set is lower at a value of 3.2. The small MAX errors also indicate, together with the small MAD errors, that the GAMESS ccCA-S4 method provides acceptable results.

In Table III, for all species in the G2-1 set using the ccCA-CC $(2,3)$ method, in which CR-CC $(2,3)$ is consistently used for closed- as well as for open-shell species (designated in Table III as GROS4-CC(2,3)), the MAD between the GROS4-CC $(2,3)$ data and experiment is $0.9 \mathrm{kcal} / \mathrm{mol}$ $(0.1 \mathrm{kcal} / \mathrm{mol}$ greater than the MAD from ccCA-S4); that between GROS4-CC $(2,3)$ and uROS4 is $0.9 \mathrm{kcal} / \mathrm{mol}$; and that between uROS4 and experiment is $0.8 \mathrm{kcal} / \mathrm{mol}$. For only singlet species, the MAD between GROS4-CC $(2,3)$ and experiment is $0.9 \mathrm{kcal} / \mathrm{mol}(0.3 \mathrm{kcal} / \mathrm{mol}$ greater than the ccCAS4 MAD); that between GROS4-CC $(2,3)$ and uROS4 is $1.0 \mathrm{kcal} / \mathrm{mol}$; and that between uROS 4 and experiment is 0.8 $\mathrm{kcal} / \mathrm{mol}$, all within chemical accuracy.

The ccCA-CC(2,3) MAD value for the G2-2 set (Table IV), comparing GROS4-CC $(2,3)$ with experiment, is $2.2 \mathrm{kcal} / \mathrm{mol}$; that between GROS4-CC $(2,3)$ and uROS4 is $2.2 \mathrm{kcal} / \mathrm{mol}$; and that between uROS4 and experiment is $0.8 \mathrm{kcal} / \mathrm{mol}$. The higher MAD values are a reflection of larger errors for both the singlets and non-singlets in the G2-2 set, as shown above for ccCA-S4. For example, for ccCA$\mathrm{CC}(2,3)$, the MAD value relative to experiment for the $\mathrm{G} 2-2$ 
TABLE I. ccCA-S4 heats of formation and MAD ${ }^{\mathrm{a}}$ values (kcal/mol) for the G2-1 set compared with experiment (expt.), GROS4, and uROS4.

\begin{tabular}{|c|c|c|c|c|c|c|c|}
\hline \multirow{2}{*}{$\begin{array}{l}\text { G2-1 Set } \\
\text { Species }\end{array}$} & \multirow[b]{2}{*}{ Multiplicity } & \multicolumn{6}{|c|}{ ccCA-S4 $\Delta \mathrm{H}_{f}(298 \mathrm{~K})(\mathrm{kcal} / \mathrm{mol})$} \\
\hline & & Expt. (1) & GROS4 (2) & uROS4 (3) & (2)-(1) & (2)-(3) & (3)-(1) \\
\hline $\mathrm{LiH}$ & 1 & 33.3 & 32.4 & 32.4 & -0.9 & 0.0 & -0.9 \\
\hline $\mathrm{BeH}$ & 2 & 81.7 & 81.6 & 81.0 & -0.1 & 0.6 & -0.7 \\
\hline $\mathrm{CH}$ & 2 & 142.5 & 142.5 & 142.3 & -0.1 & 0.1 & -0.2 \\
\hline $\mathrm{CH}_{2}$ & 3 & 93.7 & 94.2 & 94.2 & 0.5 & 0.0 & 0.5 \\
\hline $\mathrm{CH}_{2}$ & 1 & 102.8 & 102.4 & 102.3 & -0.5 & 0.1 & -0.5 \\
\hline $\mathrm{CH}_{3}$ & 2 & 35.0 & 35.0 & 35.0 & 0.0 & 0.0 & 0.0 \\
\hline $\mathrm{CH}_{4}$ & 1 & -17.9 & -17.9 & -18.0 & 0.0 & 0.1 & -0.1 \\
\hline $\mathrm{NH}$ & 3 & 85.2 & 85.7 & 85.9 & 0.5 & -0.1 & 0.7 \\
\hline $\mathrm{NH}_{2}$ & 2 & 45.1 & 44.2 & 44.2 & -0.9 & 0.0 & -0.9 \\
\hline $\mathrm{NH}_{3}$ & 1 & -11.0 & -11.7 & -11.6 & -0.7 & -0.1 & -0.6 \\
\hline $\mathrm{OH}$ & 2 & 9.4 & 8.9 & 8.6 & -0.5 & 0.2 & -0.8 \\
\hline $\mathrm{OH}_{2}$ & 1 & -57.8 & -58.8 & -59.0 & -1.0 & 0.2 & -1.2 \\
\hline $\mathrm{FH}$ & 1 & -65.1 & -66.0 & -66.1 & -0.9 & 0.0 & -1.0 \\
\hline $\mathrm{SiH}_{2}$ & 1 & 65.2 & 64.1 & 63.0 & -1.1 & 1.1 & -2.2 \\
\hline $\mathrm{SiH}_{2}$ & 3 & 86.2 & 87.3 & 86.1 & 1.1 & 1.2 & -0.1 \\
\hline $\mathrm{SiH}_{3}$ & 2 & 47.9 & 48.0 & 46.8 & 0.1 & 1.2 & -1.1 \\
\hline $\mathrm{SiH}_{4}$ & 1 & 8.2 & 7.5 & 6.3 & -0.7 & 1.2 & -1.9 \\
\hline $\mathrm{PH}_{2}$ & 2 & 33.1 & 32.0 & 32.4 & -1.1 & -0.4 & -0.7 \\
\hline $\mathrm{PH}_{3}$ & 1 & 1.3 & 1.3 & 1.5 & 0.0 & -0.2 & 0.2 \\
\hline $\mathrm{SH}_{2}$ & 1 & -4.9 & -5.5 & -5.9 & -0.6 & 0.3 & -1.0 \\
\hline $\mathrm{ClH}$ & 1 & -22.1 & -22.5 & -22.6 & -0.4 & 0.1 & -0.5 \\
\hline $\mathrm{Li}_{2}$ & 1 & 51.6 & 50.5 & 50.5 & -1.1 & 0.0 & -1.1 \\
\hline $\mathrm{LiF}$ & 1 & -80.1 & -81.9 & -82.0 & -1.8 & 0.1 & -1.9 \\
\hline $\mathrm{C}_{2} \mathrm{H}_{2}$ & 1 & 54.2 & 55.4 & 55.2 & 1.2 & 0.3 & 1.0 \\
\hline $\mathrm{C}_{2} \mathrm{H}_{4}$ & 1 & 12.5 & 12.7 & 12.5 & 0.2 & 0.2 & 0.0 \\
\hline $\mathrm{C}_{2} \mathrm{H}_{6}$ & 1 & -20.1 & -20.3 & -20.4 & -0.2 & 0.1 & -0.3 \\
\hline $\mathrm{CN}$ & 2 & 104.9 & 107.5 & 108.2 & 2.6 & -0.7 & 3.3 \\
\hline $\mathrm{HCN}$ & 1 & 31.5 & 31.6 & 31.5 & 0.1 & 0.2 & 0.0 \\
\hline $\mathrm{CO}$ & 1 & -26.4 & -26.3 & -26.8 & 0.1 & 0.5 & -0.4 \\
\hline $\mathrm{HCO}$ & 2 & 10.0 & 11.3 & 10.0 & 1.3 & 1.2 & 0.0 \\
\hline $\mathrm{H}_{2} \mathrm{CO}$ & 1 & -26.0 & -26.2 & -26.5 & -0.2 & 0.4 & -0.5 \\
\hline $\mathrm{H}_{3} \mathrm{COH}$ & 1 & -48.0 & -48.7 & -48.9 & -0.7 & 0.2 & -0.9 \\
\hline $\mathrm{N}_{2}$ & 1 & 0.0 & 0.0 & -0.2 & 0.0 & 0.2 & -0.2 \\
\hline $\mathrm{H}_{2} \mathrm{NNH}_{2}$ & 1 & 22.8 & 22.1 & 22.1 & -0.7 & 0.0 & -0.7 \\
\hline NO & 2 & 21.6 & 23.2 & 22.3 & 1.6 & 0.9 & 0.7 \\
\hline $\mathrm{O}_{2}$ & 3 & 0.0 & 1.7 & 1.1 & 1.7 & 0.6 & 1.1 \\
\hline $\mathrm{HOOH}$ & 1 & -32.5 & -32.8 & -33.1 & -0.3 & 0.3 & -0.6 \\
\hline $\mathrm{F}_{2}$ & 1 & 0.0 & 0.9 & 0.9 & 0.9 & 0.0 & 0.9 \\
\hline $\mathrm{CO}_{2}$ & 1 & -94.1 & -93.4 & -94.0 & 0.7 & 0.6 & 0.1 \\
\hline $\mathrm{Na}_{2}$ & 1 & 34.0 & 32.5 & 32.9 & -1.5 & -0.3 & -1.1 \\
\hline $\mathrm{Si}_{2}$ & 3 & 139.9 & 142.9 & 140.3 & 3.0 & 2.7 & 0.4 \\
\hline $\mathrm{P}_{2}$ & 1 & 34.3 & 35.4 & 35.5 & 1.1 & -0.2 & 1.2 \\
\hline $\mathrm{S}_{2}$ & 3 & 30.7 & 32.4 & 30.9 & 1.7 & 1.4 & 0.2 \\
\hline $\mathrm{Cl}_{2}$ & 1 & 0.0 & 0.3 & 0.1 & 0.3 & 0.2 & 0.1 \\
\hline $\mathrm{NaCl}$ & 1 & -43.6 & -43.3 & -43.2 & 0.3 & -0.1 & 0.4 \\
\hline $\mathrm{SiO}$ & 1 & -24.6 & -22.6 & -23.8 & 2.0 & 1.2 & 0.8 \\
\hline $\mathrm{SC}$ & 1 & 66.9 & 67.5 & 66.8 & 0.6 & 0.7 & -0.1 \\
\hline SO & 3 & 1.2 & 3.3 & 2.1 & 2.1 & 1.2 & 0.9 \\
\hline $\mathrm{ClO}$ & 2 & 24.2 & 27.1 & 25.8 & 2.9 & 1.3 & 1.6 \\
\hline $\mathrm{FCl}$ & 1 & -13.2 & -13.4 & -13.6 & -0.2 & 0.2 & -0.4 \\
\hline $\mathrm{Si}_{2} \mathrm{H}_{6}$ & 1 & 19.1 & 18.5 & 16.1 & -0.6 & 2.3 & -3.0 \\
\hline $\mathrm{CH}_{3} \mathrm{Cl}$ & 1 & -19.6 & -19.9 & -20.1 & -0.3 & 0.2 & -0.5 \\
\hline $\mathrm{H}_{3} \mathrm{CSH}$ & 1 & -5.5 & -5.9 & -6.3 & -0.4 & 0.4 & -0.8 \\
\hline $\mathrm{HOCl}$ & 1 & -17.8 & -18.6 & -18.9 & -0.8 & 0.3 & -1.1 \\
\hline \multirow[t]{3}{*}{$\mathrm{SO}_{2}$} & 1 & -71.0 & -70.2 & -70.7 & 0.8 & 0.5 & 0.3 \\
\hline & & & MAD of G2-1 & & 0.8 & 0.5 & 0.8 \\
\hline & & & MAD singlet species & & 0.6 & 0.4 & 0.8 \\
\hline
\end{tabular}

${ }^{a}$ The MAD values are reported between each of the three data sets as explained in the text. MAD G2-1 is the MAD for the whole G2-1 set and MAD singlet species is for all of the singlet species in the G2-1 set. 
TABLE II. ccCA-S4 heats of formation and corresponding MAD ${ }^{\mathrm{a}}$ values (kcal/mol) for the G2-2 set comparing experiment (expt.), GROS4, and uROS4.

\begin{tabular}{|c|c|c|c|c|c|c|c|}
\hline \multirow{2}{*}{$\begin{array}{l}\text { G2-2 Set } \\
\text { Species }\end{array}$} & \multirow[b]{2}{*}{ Multiplicity } & \multicolumn{6}{|c|}{ ccCA-S4 $\Delta \mathrm{H}_{f}(298 \mathrm{~K})(\mathrm{kcal} / \mathrm{mol})$} \\
\hline & & Expt. (1) & GROS4(2) & uROS4 (3) & (2)-(1) & (2)-(3) & (3)-(1) \\
\hline $\mathrm{BF}_{3}$ & 1 & -271.4 & -270.9 & -269.7 & 0.5 & -1.2 & 1.7 \\
\hline $\mathrm{BCl}_{3}$ & 1 & -96.3 & -95.9 & -95.4 & 0.4 & -0.6 & 0.9 \\
\hline $\mathrm{AlF}_{3}$ & 1 & -289.0 & -287.1 & -289.9 & 1.9 & 2.9 & -0.9 \\
\hline $\mathrm{AlCl}_{3}$ & 1 & -139.7 & -138.0 & -140.9 & 1.7 & 2.9 & -1.2 \\
\hline $\mathrm{CF}_{4}$ & 1 & -223.0 & -222.9 & -223.1 & 0.1 & 0.2 & -0.1 \\
\hline $\mathrm{CCl}_{4}$ & 1 & -22.9 & -22.2 & -22.9 & 0.7 & 0.7 & 0.0 \\
\hline $\cos$ & 1 & -33.1 & -33.4 & -34.3 & -0.3 & 0.9 & -1.2 \\
\hline $\mathrm{CS}_{2}$ & 1 & 28.0 & 28.1 & 27.0 & 0.1 & 1.1 & -1.0 \\
\hline $\mathrm{CF}_{2} \mathrm{O}$ & 1 & -149.1 & -144.5 & -144.9 & 4.6 & 0.4 & 4.2 \\
\hline $\mathrm{SiF}_{4}$ & 1 & -386.0 & -383.9 & -385.2 & 2.1 & 1.2 & 0.8 \\
\hline $\mathrm{SiCl}_{4}$ & 1 & -158.4 & -156.0 & -157.5 & 2.5 & 1.6 & 0.9 \\
\hline $\mathrm{N}_{2} \mathrm{O}$ & 1 & 19.6 & 20.2 & 19.9 & 0.6 & 0.3 & 0.3 \\
\hline $\mathrm{CINO}$ & 1 & 12.4 & 13.8 & 13.3 & 1.4 & 0.5 & 0.9 \\
\hline $\mathrm{NF}_{3}$ & 1 & -31.6 & -31.1 & -31.2 & 0.5 & 0.1 & 0.4 \\
\hline $\mathrm{PF}_{3}$ & 1 & -229.1 & -227.8 & -227.6 & 1.3 & -0.2 & 1.5 \\
\hline $\mathrm{O}_{3}$ & 1 & 34.1 & 36.6 & 36.1 & 2.5 & 0.6 & 2.0 \\
\hline $\mathrm{F}_{2} \mathrm{O}$ & 1 & 5.9 & 7.1 & 6.9 & 1.2 & 0.1 & 1.0 \\
\hline $\mathrm{ClF}_{3}$ & 1 & -38.0 & -38.4 & -38.7 & -0.4 & 0.3 & -0.7 \\
\hline $\mathrm{C}_{2} \mathrm{~F}_{4}$ & 1 & -157.4 & -160.2 & -160.7 & -2.8 & 0.5 & -3.3 \\
\hline $\mathrm{C}_{2} \mathrm{Cl}_{4}$ & 1 & -3.0 & -4.4 & -5.3 & -1.4 & 0.9 & -2.3 \\
\hline $\mathrm{CF}_{3} \mathrm{CN}$ & 1 & -118.4 & -117.6 & -118.1 & 0.8 & 0.5 & 0.3 \\
\hline Propyne & 1 & 44.2 & 45.3 & 44.9 & 1.1 & 0.4 & 0.7 \\
\hline Allene & 1 & 45.5 & 46.3 & 46.0 & 0.8 & 0.3 & 0.5 \\
\hline Cyclopropene & 1 & 66.2 & 68.7 & 68.4 & 2.5 & 0.3 & 2.2 \\
\hline Propylene & 1 & 4.8 & 5.1 & 4.8 & 0.3 & 0.3 & 0.0 \\
\hline Cyclopropane & 1 & 12.7 & 13.3 & 12.9 & 0.6 & 0.4 & 0.2 \\
\hline Propane & 1 & -25.0 & -25.3 & -25.5 & -0.3 & 0.2 & -0.5 \\
\hline Butadiene & 1 & 26.3 & 27.8 & 27.1 & 1.5 & 0.6 & 0.8 \\
\hline 2-Butyne & 1 & 34.8 & 36.6 & 36.1 & 1.8 & 0.5 & 1.3 \\
\hline Methylene cyclopropane & 1 & 47.9 & 47.3 & 46.8 & -0.6 & 0.5 & -1.1 \\
\hline Bicyclobutane & 1 & 51.9 & 54.7 & 54.1 & 2.8 & 0.6 & 2.2 \\
\hline Cyclobutene & 1 & 37.4 & 39.5 & 39.0 & 2.1 & 0.5 & 1.6 \\
\hline Cyclobutane & 1 & 6.8 & 7.0 & 6.5 & 0.2 & 0.5 & -0.3 \\
\hline Isobutene & 1 & -4.0 & -3.1 & -3.9 & 0.9 & 0.8 & 0.1 \\
\hline Transbutane & 1 & -30.0 & -30.0 & -30.6 & 0.0 & 0.5 & -0.6 \\
\hline Isobutane & 1 & -32.1 & -32.0 & -32.4 & 0.1 & 0.3 & -0.3 \\
\hline Spiropentane & 1 & 44.3 & 45.3 & 44.7 & 1.0 & 0.6 & 0.4 \\
\hline Benzene & 1 & 19.7 & 21.8 & 20.8 & 2.1 & 1.0 & 1.1 \\
\hline $\mathrm{CH}_{2} \mathrm{~F}_{2}$ & 1 & -107.7 & -108.0 & -108.1 & -0.3 & 0.1 & -0.4 \\
\hline $\mathrm{CHF}_{3}$ & 1 & -166.6 & -166.5 & -166.7 & 0.1 & 0.2 & -0.1 \\
\hline $\mathrm{CH}_{2} \mathrm{Cl}_{2}$ & 1 & -22.8 & -22.6 & -22.9 & 0.2 & 0.3 & -0.1 \\
\hline $\mathrm{CHCl}_{3}$ & 1 & -24.7 & -23.9 & -24.4 & 0.8 & 0.5 & 0.3 \\
\hline Methylamine & 1 & -5.5 & -5.7 & -5.8 & -0.2 & 0.1 & -0.3 \\
\hline Methyl cyanide & 1 & 17.7 & 18.4 & 18.1 & 0.7 & 0.3 & 0.4 \\
\hline Nitromethane & 1 & -17.8 & -17.2 & -17.8 & 0.6 & 0.6 & 0.0 \\
\hline Methyl nitrite & 1 & -15.9 & -15.5 & -16.0 & 0.4 & 0.5 & -0.1 \\
\hline Methyl silane & 1 & -7.0 & -6.3 & -7.5 & 0.7 & 1.2 & -0.5 \\
\hline Formic acid & 1 & -90.5 & -90.4 & -91.0 & 0.1 & 0.6 & -0.5 \\
\hline Methyl formate & 1 & -85.0 & -84.9 & -86.1 & 0.1 & 1.2 & -1.1 \\
\hline Acetamide & 1 & -57.0 & -55.4 & -56.6 & 1.6 & 1.2 & 0.4 \\
\hline Aziridine & 1 & 30.2 & 30.5 & 30.2 & 0.3 & 0.3 & 0.0 \\
\hline Cyanogen & 1 & 73.3 & 75.9 & 75.3 & 2.6 & 0.6 & 2.0 \\
\hline Dimethylamine & 1 & -4.4 & -3.5 & -4.5 & 0.9 & 1.0 & -0.1 \\
\hline Ethylamine & 1 & -11.3 & -11.6 & -12.6 & -0.3 & 0.9 & -1.3 \\
\hline Ketene & 1 & -11.4 & -10.7 & -11.2 & 0.7 & 0.5 & 0.2 \\
\hline Oxirane & 1 & -12.6 & -12.4 & -12.7 & 0.2 & 0.4 & -0.1 \\
\hline Acetaldehyde & 1 & -39.7 & -39.3 & -39.8 & 0.4 & 0.4 & -0.1 \\
\hline
\end{tabular}


TABLE II. (Continued.)

\begin{tabular}{|c|c|c|c|c|c|c|c|}
\hline \multirow{2}{*}{$\begin{array}{l}\text { G2-2 Set } \\
\text { Species }\end{array}$} & \multirow[b]{2}{*}{ Multiplicity } & \multicolumn{6}{|c|}{ ccCA-S4 $\Delta \mathrm{H}_{f}(298 \mathrm{~K})(\mathrm{kcal} / \mathrm{mol})$} \\
\hline & & Expt. (1) & GROS4(2) & uROS4 (3) & (2)-(1) & $(2)-(3)$ & (3)-(1) \\
\hline Glyoxal & 1 & -50.7 & -50.2 & -51.0 & 0.5 & 0.8 & -0.3 \\
\hline Ethanol & 1 & -56.2 & -55.9 & -57.0 & 0.3 & 1.1 & -0.8 \\
\hline Dimethylether & 1 & -44.0 & -43.5 & -44.5 & 0.5 & 1.1 & -0.5 \\
\hline Thiirane & 1 & 19.6 & 18.5 & 17.8 & -1.2 & 0.6 & -1.8 \\
\hline Dimethyl sulfoxide & 1 & -36.2 & -36.1 & -36.7 & 0.1 & 0.6 & -0.5 \\
\hline Ethanethiol & 1 & -11.1 & -10.5 & -11.7 & 0.6 & 1.3 & -0.6 \\
\hline Dimethylsulfide & 1 & -8.9 & -8.8 & -9.9 & 0.1 & 1.1 & -1.0 \\
\hline Vinyl fluoride & 1 & -33.2 & -33.8 & -34.0 & -0.6 & 0.2 & -0.8 \\
\hline Ethyl chloride & 1 & -26.8 & -26.9 & -27.2 & -0.1 & 0.3 & -0.4 \\
\hline Vinyl chloride & 1 & 8.9 & 5.6 & 5.2 & -3.3 & 0.4 & -3.7 \\
\hline Acrylonitrile & 1 & 43.2 & 46.3 & 45.8 & 3.1 & 0.5 & 2.6 \\
\hline Acetone & 1 & -51.9 & -51.3 & -51.9 & 0.6 & 0.5 & 0.0 \\
\hline Acetic acid & 1 & -103.4 & -102.7 & -103.4 & 0.7 & 0.7 & 0.0 \\
\hline Acetyl fluoride & 1 & -105.7 & -104.6 & -105.1 & 1.1 & 0.5 & 0.6 \\
\hline Acetyl chloride & 1 & -58.0 & -57.1 & -57.7 & 1.0 & 0.7 & 0.3 \\
\hline Propyl chloride & 1 & -31.5 & -32.0 & -32.3 & -0.5 & 0.3 & -0.8 \\
\hline Isopropanol & 1 & -65.2 & -64.6 & -66.1 & 0.6 & 1.5 & -0.9 \\
\hline Methylethyl ether & 1 & -51.7 & -51.3 & -52.7 & 0.4 & 1.4 & -1.0 \\
\hline Trimethylamine & 1 & -5.7 & -6.1 & -6.3 & -0.4 & 0.2 & -0.6 \\
\hline Furan & 1 & -8.3 & -6.3 & -7.7 & 2.1 & 1.4 & 0.6 \\
\hline Thiophene & 1 & 27.5 & 29.1 & 27.4 & 1.6 & 1.7 & -0.1 \\
\hline Pyrrole & 1 & 25.9 & 27.7 & 26.3 & 1.8 & 1.3 & 0.4 \\
\hline Pyridine & 1 & 33.6 & 35.5 & 34.6 & 1.9 & 0.8 & 1.0 \\
\hline $\mathrm{H}_{2}$ & 1 & 0.0 & -0.4 & -0.4 & -0.4 & -0.1 & -0.4 \\
\hline HS & 2 & 34.2 & 34.4 & 34.1 & 0.1 & 0.3 & -0.1 \\
\hline $\mathrm{CCH}$ & 2 & 135.1 & 136.8 & 137.7 & 1.7 & -0.8 & 2.6 \\
\hline $\mathrm{C}_{2} \mathrm{H}_{3}$ & 2 & 71.6 & 72.6 & 72.1 & 1.0 & 0.5 & 0.5 \\
\hline $\mathrm{CH}_{3} \mathrm{CO}$ & 2 & -2.4 & -0.5 & -2.2 & 1.9 & 1.7 & 0.2 \\
\hline $\mathrm{H}_{2} \mathrm{COH}$ & 2 & -4.1 & -3.3 & -4.3 & 0.8 & 1.0 & -0.2 \\
\hline $\mathrm{CH}_{3} \mathrm{O}$ & 2 & 5.0 & 5.1 & 5.0 & 0.1 & 0.0 & 0.0 \\
\hline $\mathrm{CH}_{3} \mathrm{CH}_{2} \mathrm{O}$ & 2 & -3.3 & -0.4 & -3.6 & 2.9 & 3.2 & -0.3 \\
\hline $\mathrm{CH}_{3} \mathrm{~S}$ & 2 & 29.8 & 30.0 & 29.1 & 0.2 & 0.9 & -0.7 \\
\hline $\mathrm{C}_{2} \mathrm{H}_{5}$ & 2 & 28.9 & 29.6 & 29.0 & 0.7 & 0.6 & 0.1 \\
\hline$\left(\mathrm{CH}_{3}\right)_{2} \mathrm{CH}$ & 2 & 21.5 & 23.6 & 21.5 & 2.1 & 2.1 & 0.0 \\
\hline$\left(\mathrm{CH}_{3}\right)_{3} \mathrm{C}$ & 2 & 12.3 & 14.7 & 13.1 & 2.4 & 1.6 & 0.8 \\
\hline \multirow[t]{7}{*}{$\mathrm{NO}_{2}$} & 2 & 7.9 & 11.9 & 9.0 & 4.0 & 2.9 & 1.1 \\
\hline & & & MAD G2-2 & & 1.1 & 0.8 & 0.8 \\
\hline & & & MAD G2-2 singlets & & 1.1 & 0.7 & 0.8 \\
\hline & & & MAD G2 set & & 1.0 & 0.7 & 0.8 \\
\hline & & & MAD G2 set singlets & & 0.9 & 0.6 & 0.8 \\
\hline & & & MAD G2-2 non-singlets & & 1.5 & 1.3 & 0.6 \\
\hline & & & MAX error G2 set & & 4.6 & 3.2 & 4.2 \\
\hline
\end{tabular}

aThe MAD values are reported between each of the three data sets as explained in the text. The five consecutive MAD labels at the end of the table are, respectively, the MAD for all species in the G2-2 set, the MAD for all singlet species in the G2-2 set, the MAD for all species in the G2/97 set, the MAD for all singlet species in the G2/97 set, and the MAD for non-singlet species in the G2-2 set. The maximum (MAX) error is given for all species in the G2/97 set.

singlet species is $2.4 \mathrm{kcal} / \mathrm{mol}$, which is an increase of 1.5 $\mathrm{kcal} / \mathrm{mol}$ in MAD error from the ccCA-CC $(2,3) \mathrm{G} 2-1$ set values, and reflects the more complex structures that are considered in the G2-2 set. On the other hand, the MAD between GROS4-CC $(2,3)$ and experiment, for the G2-2 non-singlet species is $0.9 \mathrm{kcal} / \mathrm{mol}$. This is an improvement over the ccCA-S4 G2-2 non-singlet species by $0.6 \mathrm{kcal} / \mathrm{mol}$. Overall, Table IV indicates that for ccCA-CC $(2,3)$ the G2/97 set MAD between GROS4-CC $(2,3)$ and experiment is $1.7 \mathrm{kcal} / \mathrm{mol}$; that between GROS4-CC $(2,3)$ and uROS4 is $1.7 \mathrm{kcal} / \mathrm{mol}$; and that between uROS4 and experiment is $0.8 \mathrm{kcal} / \mathrm{mol}$. The ccCA-CC $(2,3)$ method improves on the predicted heats of formation of the doublet species, for example, for $\mathrm{NO}_{2}$ the absolute difference from experiment for the ccCA-S4 heats of formation is $4.0 \mathrm{kcal} / \mathrm{mol}$ vs. $1.7 \mathrm{kcal} / \mathrm{mol}$ for ccCA-CC(2,3). For $\left(\mathrm{CH}_{3}\right)_{3} \mathrm{C}$, the analogous improvement is $2.4 \mathrm{kcal} / \mathrm{mol}(\mathrm{ccCA}$ $\mathrm{S} 4)$ to $0.5 \mathrm{kcal} / \mathrm{mol}$ (ccCA-CC $(2,3)$ ).

The MAX error for all species in the G2/97 set between GROS4-CC $(2,3)$ and experiment increased by $2.6 \mathrm{kcal} / \mathrm{mol}$ compared to the same MAX error between 
TABLE III. ccCA-CC(2,3) heats of formation and MAD ${ }^{\mathrm{a}}$ values (kcal/mol) of the G2-1 set from experiment (expt.), GROS4-CC(2,3), and uROS4.

\begin{tabular}{|c|c|c|c|c|c|c|c|}
\hline \multirow{2}{*}{$\begin{array}{l}\text { G2-1 Set } \\
\text { Species }\end{array}$} & \multirow[b]{2}{*}{ Multiplicity } & \multicolumn{6}{|c|}{$\operatorname{ccCA}-\mathrm{CC}(2,3) \Delta \mathrm{H}_{f}(298 \mathrm{~K}) \mathrm{kcal} / \mathrm{mol}$} \\
\hline & & Expt. (1) & GROS4-CC(2,3)(2) & uROS4 (3) & $(2)-(1)$ & (2)-(3) & (3)-(1) \\
\hline $\mathrm{LiH}$ & 1 & 33.3 & 32.4 & 32.4 & -0.9 & 0.0 & -0.9 \\
\hline $\mathrm{BeH}$ & 2 & 81.7 & 81.6 & 81.0 & -0.1 & 0.5 & -0.7 \\
\hline $\mathrm{CH}$ & 2 & 142.5 & 142.4 & 142.3 & -0.2 & 0.0 & -0.2 \\
\hline $\mathrm{CH}_{2}$ & 3 & 93.7 & 94.3 & 94.2 & 0.6 & 0.1 & 0.5 \\
\hline $\mathrm{CH}_{2}$ & 1 & 102.8 & 102.5 & 102.3 & -0.3 & 0.2 & -0.5 \\
\hline $\mathrm{CH}_{3}$ & 2 & 35.0 & 35.1 & 35.0 & 0.1 & 0.1 & 0.0 \\
\hline $\mathrm{CH}_{4}$ & 1 & -17.9 & -17.4 & -18.0 & 0.5 & 0.5 & -0.1 \\
\hline $\mathrm{NH}$ & 3 & 85.2 & 85.6 & 85.9 & 0.4 & -0.2 & 0.7 \\
\hline $\mathrm{NH}_{2}$ & 2 & 45.1 & 44.2 & 44.2 & -0.9 & -0.1 & -0.9 \\
\hline $\mathrm{NH}_{3}$ & 1 & -11.0 & -11.3 & -11.6 & -0.3 & 0.3 & -0.6 \\
\hline $\mathrm{OH}$ & 2 & 9.4 & 8.9 & 8.6 & -0.5 & 0.2 & -0.8 \\
\hline $\mathrm{OH}_{2}$ & 1 & -57.8 & -58.4 & -59.0 & -0.6 & 0.6 & -1.2 \\
\hline $\mathrm{FH}$ & 1 & -65.1 & -65.7 & -66.1 & -0.6 & 0.4 & -1.0 \\
\hline $\mathrm{SiH}_{2}$ & 1 & 65.2 & 64.4 & 63.0 & -0.8 & 1.4 & -2.2 \\
\hline $\mathrm{SiH}_{2}$ & 3 & 86.2 & 87.4 & 86.1 & 1.2 & 1.3 & -0.1 \\
\hline $\mathrm{SiH}_{3}$ & 2 & 47.9 & 48.3 & 46.8 & 0.4 & 1.5 & -1.1 \\
\hline $\mathrm{SiH}_{4}$ & 1 & 8.2 & 8.1 & 6.3 & -0.1 & 1.8 & -1.9 \\
\hline $\mathrm{PH}_{2}$ & 2 & 33.1 & 32.0 & 32.4 & -1.1 & -0.4 & -0.7 \\
\hline $\mathrm{PH}_{3}$ & 1 & 1.3 & 1.8 & 1.5 & 0.5 & 0.2 & 0.2 \\
\hline $\mathrm{SH}_{2}$ & 1 & -4.9 & -5.1 & -5.9 & -0.2 & 0.8 & -1.0 \\
\hline $\mathrm{ClH}$ & 1 & -22.1 & -22.0 & -22.6 & 0.1 & 0.5 & -0.5 \\
\hline $\mathrm{Li}_{2}$ & 1 & 51.6 & 50.5 & 50.5 & -1.1 & 0.0 & -1.1 \\
\hline $\mathrm{LiF}$ & 1 & -80.1 & -81.4 & -82.0 & -1.3 & 0.6 & -1.9 \\
\hline $\mathrm{C}_{2} \mathrm{H}_{2}$ & 1 & 54.2 & 56.1 & 55.2 & 1.9 & 0.9 & 1.0 \\
\hline $\mathrm{C}_{2} \mathrm{H}_{4}$ & 1 & 12.5 & 13.6 & 12.5 & 1.1 & 1.1 & 0.0 \\
\hline $\mathrm{C}_{2} \mathrm{H}_{6}$ & 1 & -20.1 & -19.1 & -20.4 & 1.0 & 1.3 & -0.3 \\
\hline $\mathrm{CN}$ & 2 & 104.9 & 106.1 & 108.2 & 1.2 & -2.1 & 3.3 \\
\hline $\mathrm{HCN}$ & 1 & 31.5 & 32.2 & 31.5 & 0.6 & 0.7 & 0.0 \\
\hline $\mathrm{CO}$ & 1 & -26.4 & -26.0 & -26.8 & 0.4 & 0.9 & -0.4 \\
\hline $\mathrm{HCO}$ & 2 & 10.0 & 10.8 & 10.0 & 0.8 & 0.7 & 0.0 \\
\hline $\mathrm{H}_{2} \mathrm{CO}$ & 1 & -26.0 & -25.4 & -26.5 & 0.6 & 1.1 & -0.5 \\
\hline $\mathrm{H}_{3} \mathrm{COH}$ & 1 & -48.0 & -47.6 & -48.9 & 0.4 & 1.3 & -0.9 \\
\hline $\mathrm{N}_{2}$ & 1 & 0.0 & 0.1 & -0.2 & 0.1 & 0.2 & -0.2 \\
\hline $\mathrm{H}_{2} \mathrm{NNH}_{2}$ & 1 & 22.8 & 23.2 & 22.1 & 0.3 & 1.0 & -0.7 \\
\hline $\mathrm{NO}$ & 2 & 21.6 & 22.0 & 22.3 & 0.4 & -0.4 & 0.7 \\
\hline $\mathrm{O}_{2}$ & 3 & 0.0 & 0.6 & 1.1 & 0.6 & -0.5 & 1.1 \\
\hline $\mathrm{HOOH}$ & 1 & -32.5 & -31.9 & -33.1 & 0.6 & 1.2 & -0.6 \\
\hline $\mathrm{F}_{2}$ & 1 & 0.0 & 1.4 & 0.9 & 1.4 & 0.5 & 0.9 \\
\hline $\mathrm{CO}_{2}$ & 1 & -94.1 & -92.7 & -94.0 & 1.4 & 1.3 & 0.1 \\
\hline $\mathrm{Na}_{2}$ & 1 & 34.0 & 32.5 & 32.9 & -1.5 & -0.3 & -1.1 \\
\hline $\mathrm{Si}_{2}$ & 3 & 139.9 & 144.6 & 140.3 & 4.7 & 4.3 & 0.4 \\
\hline $\mathrm{P}_{2}$ & 1 & 34.3 & 36.0 & 35.5 & 1.7 & 0.5 & 1.2 \\
\hline $\mathrm{S}_{2}$ & 3 & 30.7 & 31.6 & 30.9 & 0.9 & 0.7 & 0.2 \\
\hline $\mathrm{Cl}_{2}$ & 1 & 0.0 & 1.6 & 0.1 & 1.6 & 1.5 & 0.1 \\
\hline $\mathrm{NaCl}$ & 1 & -43.6 & -42.5 & -43.2 & 1.1 & 0.6 & 0.4 \\
\hline $\mathrm{SiO}$ & 1 & -24.6 & -21.3 & -23.8 & 3.3 & 2.5 & 0.8 \\
\hline $\mathrm{SC}$ & 1 & 66.9 & 67.6 & 66.8 & 0.6 & 0.8 & -0.1 \\
\hline SO & 3 & 1.2 & 2.6 & 2.1 & 1.4 & 0.5 & 0.9 \\
\hline $\mathrm{ClO}$ & 2 & 24.2 & 26.4 & 25.8 & 2.2 & 0.6 & 1.6 \\
\hline $\mathrm{FCl}$ & 1 & -13.2 & -12.6 & -13.6 & 0.6 & 1.0 & -0.4 \\
\hline $\mathrm{Si}_{2} \mathrm{H}_{6}$ & 1 & 19.1 & 19.8 & 16.1 & 0.6 & 3.6 & -3.0 \\
\hline $\mathrm{CH}_{3} \mathrm{Cl}$ & 1 & -19.6 & -18.7 & -20.1 & 0.9 & 1.4 & -0.5 \\
\hline $\mathrm{H}_{3} \mathrm{CSH}$ & 1 & -5.5 & -4.6 & -6.3 & 0.9 & 1.7 & -0.8 \\
\hline $\mathrm{HOCl}$ & 1 & -17.8 & -17.6 & -18.9 & 0.3 & 1.4 & -1.1 \\
\hline \multirow[t]{3}{*}{$\mathrm{SO}_{2}$} & 1 & -71.0 & -68.6 & -70.7 & 2.4 & 2.1 & 0.3 \\
\hline & & & MAD G2-1 & & 0.9 & 0.9 & 0.8 \\
\hline & & & MAD singlet species & & 0.9 & 1.0 & 0.8 \\
\hline
\end{tabular}

${ }^{a}$ The MAD values are reported between each of the three data sets as explained in the text. MAD G2-1 is the MAD for the whole G2-1 set and MAD singlet species is for all of the singlet species in the G2-1 set. 
TABLE IV. ccCA-CC(2,3) heats of formation and MAD ${ }^{\mathrm{a}}$ values (kcal/mol) of the G2-2 set from experiment (expt.), GROS4-CC(2,3), and uROS4.

\begin{tabular}{|c|c|c|c|c|c|c|c|}
\hline \multirow{2}{*}{$\begin{array}{l}\text { G2-2 Set } \\
\text { Species }\end{array}$} & \multirow[b]{2}{*}{ Multiplicity } & \multicolumn{6}{|c|}{$\operatorname{ccCA}-\mathrm{CC}(2,3) \Delta \mathrm{H}_{f}(298 \mathrm{~K})$} \\
\hline & & Expt. (1) & GROS4-CC $(2,3)(2)$ & uROS4(3) & (2)-(1) & $(2)-(3)$ & (3)-(1) \\
\hline $\mathrm{BF}_{3}$ & 1 & -271.4 & -269.5 & -269.7 & 1.9 & 0.2 & 1.7 \\
\hline $\mathrm{BCl}_{3}$ & 1 & -96.3 & -92.9 & -95.4 & 3.4 & 2.5 & 0.9 \\
\hline $\mathrm{AlF}_{3}$ & 1 & -289.0 & -285.4 & -289.9 & 3.6 & 4.6 & -0.9 \\
\hline $\mathrm{AlCl}_{3}$ & 1 & -139.7 & -134.6 & -140.9 & 5.1 & 6.3 & -1.2 \\
\hline $\mathrm{CF}_{4}$ & 1 & -223.0 & -221.1 & -223.1 & 1.9 & 1.9 & -0.1 \\
\hline $\mathrm{CCl}_{4}$ & 1 & -22.9 & -17.7 & -22.9 & 5.2 & 5.2 & 0.0 \\
\hline $\mathrm{COS}$ & 1 & -33.1 & -32.3 & -34.3 & 0.8 & 2.0 & -1.2 \\
\hline $\mathrm{CS}_{2}$ & 1 & 28.0 & 29.7 & 27.0 & 1.7 & 2.7 & -1.0 \\
\hline $\mathrm{CF}_{2} \mathrm{O}$ & 1 & -149.1 & -143.2 & -144.9 & 5.9 & 1.7 & 4.2 \\
\hline $\mathrm{SiF}_{4}$ & 1 & -386.0 & -381.7 & -385.2 & 4.3 & 3.5 & 0.8 \\
\hline $\mathrm{SiCl}_{4}$ & 1 & -158.4 & -151.2 & -157.5 & 7.2 & 6.3 & 0.9 \\
\hline $\mathrm{N}_{2} \mathrm{O}$ & 1 & 19.6 & 20.9 & 19.9 & 1.3 & 1.1 & 0.3 \\
\hline CINO & 1 & 12.4 & 12.9 & 13.3 & 0.5 & -0.4 & 0.9 \\
\hline $\mathrm{NF}_{3}$ & 1 & -31.6 & -30.1 & -31.2 & 1.5 & 1.1 & 0.4 \\
\hline $\mathrm{PF}_{3}$ & 1 & -229.1 & -226.0 & -227.6 & 3.1 & 1.6 & 1.5 \\
\hline $\mathrm{O}_{3}$ & 1 & 34.1 & 38.3 & 36.1 & 4.2 & 2.2 & 2.0 \\
\hline $\mathrm{F}_{2} \mathrm{O}$ & 1 & 5.9 & 8.0 & 6.9 & 2.1 & 1.0 & 1.0 \\
\hline $\mathrm{ClF}_{3}$ & 1 & -38.0 & -36.4 & -38.7 & 1.6 & 2.3 & -0.7 \\
\hline $\mathrm{C}_{2} \mathrm{~F}_{4}$ & 1 & -157.4 & -157.6 & -160.7 & -0.2 & 3.1 & -3.3 \\
\hline $\mathrm{C}_{2} \mathrm{Cl}_{4}$ & 1 & -3.0 & 1.2 & -5.3 & 4.2 & 6.5 & -2.3 \\
\hline $\mathrm{CF}_{3} \mathrm{CN}$ & 1 & -118.4 & -114.8 & -118.1 & 3.6 & 3.4 & 0.3 \\
\hline Propyne & 1 & 44.2 & 46.5 & 44.9 & 2.3 & 1.6 & 0.7 \\
\hline Allene & 1 & 45.5 & 47.4 & 46.0 & 1.9 & 1.4 & 0.5 \\
\hline Cyclopropene & 1 & 66.2 & 69.8 & 68.4 & 3.6 & 1.4 & 2.2 \\
\hline Propylene & 1 & 4.8 & 6.2 & 4.8 & 1.4 & 1.4 & 0.0 \\
\hline Cyclopropane & 1 & 12.7 & 14.4 & 12.9 & 1.7 & 1.4 & 0.2 \\
\hline Propane & 1 & -25.0 & -24.2 & -25.5 & 0.8 & 1.2 & -0.5 \\
\hline Butadiene & 1 & 26.3 & 29.6 & 27.1 & 3.3 & 2.4 & 0.8 \\
\hline 2-Butyne & 1 & 34.8 & 38.4 & 36.1 & 3.6 & 2.3 & 1.3 \\
\hline Methylene cyclopropane & 1 & 47.9 & 49.1 & 46.8 & 1.2 & 2.3 & -1.1 \\
\hline Bicyclobutane & 1 & 51.9 & 56.4 & 54.1 & 4.5 & 2.3 & 2.2 \\
\hline Cyclobutene & 1 & 37.4 & 41.2 & 39.0 & 3.8 & 2.2 & 1.6 \\
\hline Cyclobutane & 1 & 6.8 & 8.6 & 6.5 & 1.8 & 2.1 & -0.3 \\
\hline Isobutene & 1 & -4.0 & -1.4 & -3.9 & 2.6 & 2.5 & 0.1 \\
\hline Transbutane & 1 & -30.0 & -28.5 & -30.6 & 1.5 & 2.1 & -0.6 \\
\hline Isobutane & 1 & -32.1 & -30.4 & -32.4 & 1.7 & 2.0 & -0.3 \\
\hline Spiropentane & 1 & 44.3 & 47.8 & 44.7 & 3.5 & 3.1 & 0.4 \\
\hline Benzene & 1 & 19.7 & 25.2 & 20.8 & 5.5 & 4.4 & 1.1 \\
\hline $\mathrm{CH}_{2} \mathrm{~F}_{2}$ & 1 & -107.7 & -107.0 & -108.1 & 0.7 & 1.1 & -0.4 \\
\hline $\mathrm{CHF}_{3}$ & 1 & -166.6 & -165.1 & -166.7 & 1.5 & 1.5 & -0.1 \\
\hline $\mathrm{CH}_{2} \mathrm{Cl}_{2}$ & 1 & -22.8 & -20.6 & -22.9 & 2.2 & 2.3 & -0.1 \\
\hline $\mathrm{CHCl}_{3}$ & 1 & -24.7 & -20.7 & -24.4 & 4.0 & 3.7 & 0.3 \\
\hline Methylamine & 1 & -5.5 & -5.1 & -5.8 & 0.4 & 0.6 & -0.3 \\
\hline Methyl cyanide & 1 & 17.7 & 19.7 & 18.1 & 2.0 & 1.6 & 0.4 \\
\hline Nitromethane & 1 & -17.8 & -15.3 & -17.8 & 2.5 & 2.5 & 0.0 \\
\hline Methyl nitrite & 1 & -15.9 & -13.8 & -16.0 & 2.1 & 2.2 & -0.1 \\
\hline Methyl silane & 1 & -7.0 & -5.6 & -7.5 & 1.4 & 1.9 & -0.5 \\
\hline Formic acid & 1 & -90.5 & -89.3 & -91.0 & 1.2 & 1.6 & -0.5 \\
\hline Methyl formate & 1 & -85.0 & -83.7 & -86.1 & 1.3 & 2.4 & -1.1 \\
\hline Acetamide & 1 & -57.0 & -54.2 & -56.6 & 2.8 & 2.3 & 0.4 \\
\hline Aziridine & 1 & 30.2 & 31.6 & 30.2 & 1.4 & 1.4 & 0.0 \\
\hline Cyanogen & 1 & 73.3 & 77.5 & 75.3 & 4.2 & 2.2 & 2.0 \\
\hline Dimethylamine & 1 & -4.4 & -3.3 & -4.5 & 1.1 & 1.2 & -0.1 \\
\hline Ethylamine & 1 & -11.3 & -11.4 & -12.6 & -0.1 & 1.2 & -1.3 \\
\hline Ketene & 1 & -11.4 & -9.9 & -11.2 & 1.5 & 1.3 & 0.2 \\
\hline Oxirane & 1 & -12.6 & -11.3 & -12.7 & 1.3 & 1.5 & -0.1 \\
\hline Acetaldehyde & 1 & -39.7 & -38.3 & -39.8 & 1.4 & 1.5 & -0.1 \\
\hline
\end{tabular}


TABLE IV. (Continued.)

\begin{tabular}{|c|c|c|c|c|c|c|c|}
\hline \multirow{2}{*}{$\begin{array}{l}\text { G2-2 Set } \\
\text { Species }\end{array}$} & \multirow[b]{2}{*}{ Multiplicity } & \multicolumn{6}{|c|}{$\operatorname{ccCA}-\mathrm{CC}(2,3) \Delta \mathrm{H}_{f}(298 \mathrm{~K})$} \\
\hline & & Expt. (1) & GROS4-CC (2,3)(2) & uROS4(3) & $(2)-(1)$ & $(2)-(3)$ & (3)-(1) \\
\hline Glyoxal & 1 & -50.7 & -48.5 & -51.0 & 2.2 & 2.5 & -0.3 \\
\hline Ethanol & 1 & -56.2 & -55.5 & -57.0 & 0.7 & 1.5 & -0.8 \\
\hline Dimethylether & 1 & -44.0 & -43.0 & -44.5 & 1.0 & 1.5 & -0.5 \\
\hline Thiirane & 1 & 19.6 & 19.9 & 17.8 & 0.3 & 2.1 & -1.8 \\
\hline Dimethyl sulfoxide & 1 & -36.2 & -33.6 & -36.7 & 2.6 & 3.0 & -0.5 \\
\hline Ethanethiol & 1 & -11.1 & -9.7 & -11.7 & 1.5 & 2.1 & -0.6 \\
\hline Dimethylsulfide & 1 & -9.0 & -7.9 & -9.9 & 1.1 & 2.0 & -0.9 \\
\hline Vinyl fluoride & 1 & -33.2 & -32.7 & -34.0 & 0.5 & 1.3 & -0.8 \\
\hline Ethyl chloride & 1 & -26.8 & -25.4 & -27.2 & 1.4 & 1.8 & -0.4 \\
\hline Vinyl chloride & 1 & 8.9 & 7.1 & 5.2 & -1.8 & 1.9 & -3.7 \\
\hline Acrylonitrile & 1 & 43.2 & 48.2 & 45.8 & 5.0 & 2.4 & 2.6 \\
\hline Acetone & 1 & -51.9 & -49.6 & -51.9 & 2.3 & 2.3 & 0.0 \\
\hline Acetic acid & 1 & -103.4 & -100.9 & -103.4 & 2.5 & 2.5 & 0.0 \\
\hline Acetyl fluoride & 1 & -105.7 & -103.1 & -105.1 & 2.6 & 1.9 & 0.6 \\
\hline Acetyl chloride & 1 & -58.0 & -55.0 & -57.7 & 3.0 & 2.8 & 0.3 \\
\hline Propyl chloride & 1 & -31.5 & -29.8 & -32.3 & 1.7 & 2.5 & -0.8 \\
\hline Isopropanol & 1 & -65.2 & -63.8 & -66.1 & 1.4 & 2.3 & -0.9 \\
\hline Methylethyl ether & 1 & -51.7 & -50.5 & -52.7 & 1.2 & 2.2 & -1.0 \\
\hline Trimethylamine & 1 & -5.7 & -4.4 & -6.3 & 1.3 & 1.9 & -0.6 \\
\hline Furan & 1 & -8.3 & -4.3 & -7.7 & 4.0 & 3.4 & 0.6 \\
\hline Thiophene & 1 & 27.5 & 31.6 & 27.4 & 4.1 & 4.2 & -0.1 \\
\hline Pyrrole & 1 & 25.9 & 29.5 & 26.3 & 3.6 & 3.2 & 0.4 \\
\hline Pyridine & 1 & 33.6 & 39.0 & 34.6 & 5.4 & 4.4 & 1.0 \\
\hline $\mathrm{H}_{2}$ & 1 & 0.0 & -0.4 & -0.4 & -0.4 & -0.1 & -0.4 \\
\hline HS & 2 & 34.2 & 34.3 & 34.1 & 0.1 & 0.2 & -0.1 \\
\hline $\mathrm{CCH}$ & 2 & 135.1 & 135.9 & 137.7 & 0.8 & -1.8 & 2.6 \\
\hline $\mathrm{C}_{2} \mathrm{H}_{3}$ & 2 & 71.6 & 72.3 & 72.1 & 0.7 & 0.2 & 0.5 \\
\hline $\mathrm{CH}_{3} \mathrm{CO}$ & 2 & -2.4 & -0.8 & -2.2 & 1.6 & 1.4 & 0.2 \\
\hline $\mathrm{H}_{2} \mathrm{COH}$ & 2 & -4.1 & -3.3 & -4.3 & 0.8 & 1.0 & -0.2 \\
\hline $\mathrm{CH}_{3} \mathrm{O}$ & 2 & 5.0 & 4.8 & 5.0 & -0.2 & -0.3 & 0.0 \\
\hline $\mathrm{CH}_{3} \mathrm{CH}_{2} \mathrm{O}$ & 2 & -3.3 & -0.7 & -3.6 & 2.6 & 2.9 & -0.3 \\
\hline $\mathrm{CH}_{3} \mathrm{~S}$ & 2 & 29.8 & 29.8 & 29.1 & 0.0 & 0.7 & -0.7 \\
\hline $\mathrm{C}_{2} \mathrm{H}_{5}$ & 2 & 28.9 & 29.4 & 29.0 & 0.5 & 0.4 & 0.1 \\
\hline$\left(\mathrm{CH}_{3}\right)_{2} \mathrm{CH}$ & 2 & 21.5 & 22.6 & 21.5 & 1.1 & 1.1 & 0.0 \\
\hline$\left(\mathrm{CH}_{3}\right)_{3} \mathrm{C}$ & 2 & 12.3 & 12.8 & 13.1 & 0.5 & -0.2 & 0.8 \\
\hline \multirow[t]{7}{*}{$\mathrm{NO}_{2}$} & 2 & 7.9 & 9.6 & 9.0 & 1.7 & 0.6 & 1.1 \\
\hline & & & MAD G2-2 & & 2.2 & 2.1 & 0.8 \\
\hline & & & MAD G2-2 singlets & & 2.4 & 2.3 & 0.8 \\
\hline & & & MAD G2 set & & 1.7 & 1.7 & 0.8 \\
\hline & & & MAD G2 set singlets & & 1.9 & 1.9 & 0.8 \\
\hline & & & MAD G2-2 non-singlets & & 0.9 & 0.9 & 0.6 \\
\hline & & & MAX error G2 set & & 7.2 & 6.5 & 4.2 \\
\hline
\end{tabular}

${ }^{\mathrm{a}}$ The MAD values are reported between each of the three data sets as explained in the text. The five consecutive MAD labels at the end of the table are, respectively, the MAD for all species in the G2-2 set, the MAD for all singlet species in the G2-2 set, the MAD for all species in the G2/97 set, the MAD for all singlet species in the G2/97 set, and the MAD for non-singlet species in the G2-2 set. The maximum (MAX) error is given for all species in the G2/97 set.

GROS4 and experiment. Also, the MAX error for all species in the G2/97 set between GROS4-CC $(2,3)$ and uROS4 increased by $3.3 \mathrm{kcal} / \mathrm{mol}$ compared to that between GROS4 and uROS4. The discussion below discusses these acceptable increases.

GROS4 and uROS4 may appear to be the same for certain closed-shell species, but this does not imply that the energies of atomization will be the same. For example, if a closed-shell species $\mathrm{AB}$ dissociates into open-shell $\mathrm{A}$ and $\mathrm{B}$ fragments, the GROS4 energy is calculated using CCSD(T)/RHF for AB and $\mathrm{CR}-\mathrm{CC}(2,3) / \mathrm{ROHF}$ for $\mathrm{A}$ and $\mathrm{B}$. The analogous uROS4 energy uses CCSD(T)/RHF for AB and CCSD(T)/UHF for A and B. So, the energies of atomization will be different despite the fact that the total energy of $\mathrm{AB}$ may be the same in both calculations. Similarly, the fact that GROS4 and GROS4$\mathrm{CC}(2,3)$ may be the same for open shells does not mean that the atomization energies are the same, since one of the dissociation fragments could be a closed shell (so that GROS4 would use $\operatorname{CCSD}(\mathrm{T}) / \mathrm{RHF}$ and GROS4-CC $(2,3)$ would use CR-CC(2,3)/RHF for this fragment). Only if the molecule and fragments are all open shells, should GROS4 and GROS4$\mathrm{CC}(2,3)$ be expected to give the same atomization energy, since all species involved in atomization are treated by CR-CC(2,3)/ROHF (see, e.g., $\mathrm{NH}_{2}$ in Table III). 


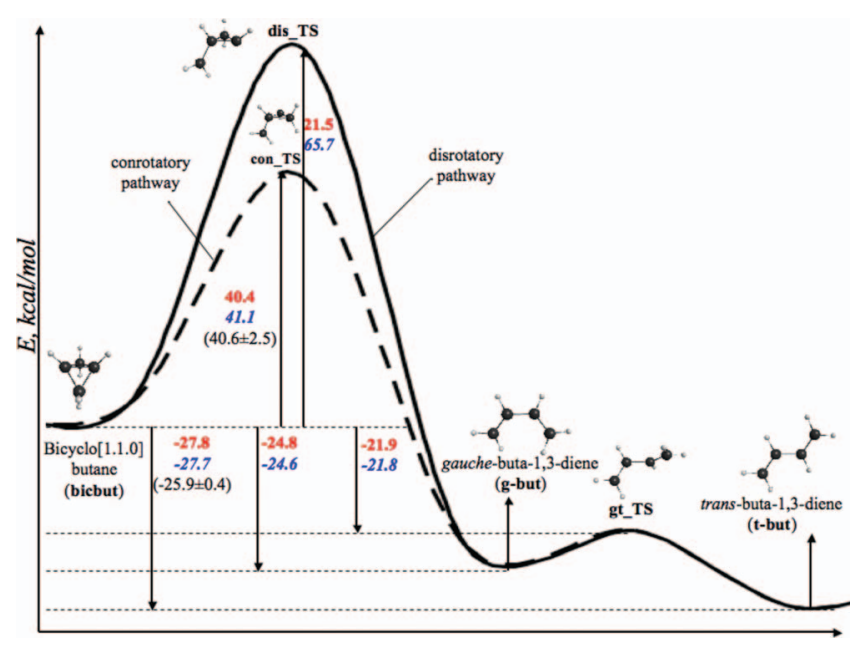

FIG. 2. The conrotatory pathway (dashed curve) and disrotatory pathway (solid curve) for the isomerization of bicyclo[1.1.0]butane to trans-buta-1,3diene. Two sets of relative energies (in $\mathrm{kcal} / \mathrm{mol}$ ) are shown, obtained from ccCA $0 \mathrm{~K}$ energies for each stationary point. Energies in red are ccCA-S4 values based on CASSCF $(10,10) / c c-p V D Z$ geometries. Energies in blue italics are ccCA-CC $(2,3)$ values based on $\operatorname{CASSCF}(10,10) / \mathrm{cc}-\mathrm{pVDZ}$ geometries. The values in parentheses represent the available experimental data.

\section{B. Pericyclic rearrangement}

Figure 2 illustrates the potential energy curves for the pericyclic rearrangement. The only available experimental data are for the conrotatory transition state and the trans-buta1,3-diene final product. The activation energy barrier for the isomerization of bicyclo[1.1.0]butane into buta-1,3-diene is $40.6 \pm 2.5 \mathrm{kcal} / \mathrm{mol}$ at $0 \mathrm{~K},{ }^{73}$ and since this isomerization is a conrotatory process, the activation energy corresponds to the conrotatory transition state. The trans-buta-1,3-diene final product has a heat of reaction that is estimated to be -25.9 $\pm 0.4 \mathrm{kcal} / \mathrm{mol}$ at $298 \mathrm{~K} .{ }^{74}$ Thus, only the conrotatory transition state and trans-buta-1,3-diene final product energies can be compared to experimental data. This lack of experimental data for the pericyclic rearrangement pathway also emphasizes the need for the development of quantitatively reliable methods to predict the energies along reaction pathways that contain diradical species. It is, therefore, gratifying that all conrotatory activation energies and the net reaction energy predicted by ccCA-S4 and ccCA-CC $(2,3)$ agree to within 1$2 \mathrm{kcal} / \mathrm{mol}$ with the experimental values (see Figure 2 and Table V).

A simple measure of the percent diradical character in a wavefunction is $\left(2-n_{\mathrm{H}}\right) \times 100$, where $n_{\mathrm{H}}$ is the occupation number of the natural orbital corresponding to the highest occupied molecular orbital. In this work, $n_{\mathrm{H}}$ was obtained from the CASSCF $(10,10) / c c-p V D Z$ wavefunction.$^{50}$ The percent diradical character for each of the relevant species in the pericyclic reaction mechanism is listed in Table V. One advantage of the CR-CC $(2,3)$ method is that, unlike traditional coupled cluster approaches, such as CCSD(T), CR-CC $(2,3)$ can correctly account for significant diradical character. This capability of the CR-CC $(2,3)$ approach is relevant in the current context, since the various species listed in Table $\mathrm{V}$ have dramatically different amounts of diradical character. So, for any method to be successful for this system, it must be able to account correctly for diradical character that varies a great deal along the reaction potential energy surface. For example, the diradical character in the conrotatory vs. the disrotatory transition state is $24 \%$ vs. $90 \%$, while the diradical character in the local minimum energy structures is less than $10 \%$. As may be seen in Table $\mathrm{V}$, this leads to large differences in predicted relative energies between CR-CC $(2,3)$ and $\operatorname{CCSD}(T)$, with $\operatorname{CCSD}(\mathrm{T})$ placing the disrotatory transition state below the conrotatory one, contradicting the well-established experimental data ${ }^{65,66}$ and MR- (Refs. 50, 67, and 69) or MR-based quantum Monte $\mathrm{Carlo}^{70}$ calculations. The agreement between these two levels of theory is much better for the conrotatory than for the disrotatory transition state due to the smaller diradical character in the former than in the latter. The above accuracy patterns characterizing the restricted $\mathrm{CR}-\mathrm{CC}(2,3)$ and $\mathrm{CCSD}(\mathrm{T})$ methods propagate into the corresponding $\mathrm{CR}$ $\mathrm{CC}(2,3)$-based ccCA-CC $(2,3)$ and $\mathrm{CCSD}(\mathrm{T})$-based ccCA-S4 calculations, where only the former ccCA scheme provides the correct energy ordering of both isomerization pathways.

The ccCA-S4 and ccCA-CC $(2,3)$ values of the reaction heat at $298 \mathrm{~K}$ were also calculated in order to compare with the available experimental reaction enthalpy, which is, as mentioned above, $-25.9 \pm 0.4 \mathrm{kcal} / \mathrm{mol}$ at $298 \mathrm{~K}^{74}$ The ccCA-S4 and ccCA-CC $(2,3)$ approaches give $-26.7 \mathrm{kcal} / \mathrm{mol}$ and $-26.6 \mathrm{kcal} / \mathrm{mol}$, respectively, using the

TABLE V. Electronic energies corrected for zero-point vibrational energies, i.e., enthalpies at $0 \mathrm{~K}^{\mathrm{a}}(\mathrm{kcal} / \mathrm{mol})$, characterizing the con_TS and dis_TS transition states, g-but intermediate, gt_TS transition state, and t-but final product at several levels of theory. All energies are relative to bicbut reactant.

\begin{tabular}{lccccc}
\hline \hline Method & con_TS & dis_TS & g-but & gt_TS & t-but \\
\hline CASSCF(10,10)/cc-pVDZ & 38.5 & 52.0 & -39.7 & -37.2 & -42.6 \\
CCSD(T)/cc-pVTZ//CASSCF(10,10)/cc-pVDZ & 40.4 & 21.8 & -25.1 & -22.3 & -28.0 \\
CR-CC(2,3)/cc-pVTZ//CASSCF(10,10)/cc-pVDZ & 41.1 & 66.1 & -24.9 & -22.1 & -27.9 \\
ccCA-S4//CASSCF(10,10)/cc-pVDZ & 40.4 & 21.5 & -24.8 & -21.9 & -27.8 \\
ccCA-CC(2,3)//CASSCF(10,10)/cc-pVDZ & 41.1 & 65.7 & -24.6 & -21.8 & -27.7 \\
Percent diradical character & 24 & 90 & 9 & 8 & 9 \\
Experiment & $40.6 \pm 2.5^{\mathrm{c}}$ & & & & $-25.9 \pm 0.4^{\mathrm{d}}$ \\
\hline \hline
\end{tabular}

a The ccCA values are based on heats of formation at $0 \mathrm{~K}$. The CASSCF and CR-CC(2,3) values are taken from Ref. 50. The A//B notation indicates an energy calculated at level A using the geometry determined at level B.

${ }^{\mathrm{b}}$ Obtained using CASSCF $(10,10) / \mathrm{cc}-\mathrm{pVDZ}$; bicbut has a diradical character of $4 \%$.

${ }^{\mathrm{c}}$ Reference 73 .

${ }^{d}$ Reaction enthalpy at $298 \mathrm{~K}$ based on the enthalpies of formation of bicyclo[1.1.0]butane and buta-1,3-diene in Ref. 74. 
CASSCF $(10,10) / c c-p V D Z$ geometries. These ccCA heats of reaction are in very good agreement with experiment and with each other.

\section{CONCLUSIONS}

Both the ccCA-S4 and ccCA-CC $(2,3)$ methods have been compared with the G2/97 set using a new code that has been developed for composite methods. The ROHF-based CR$\mathrm{CC}(2,3)$ method has been shown to be an accurate and computationally cost-effective option for the calculation of heats of formation, both within the ccCA-CC $(2,3)$ approach, in which the CR-CC $(2,3)$ method is used for closed- as well open-shell species, and within the modified ccCA-S4 protocol, in which $\operatorname{CCSD}(\mathrm{T})$ is used for closed-shell systems and CR-CC $(2,3)$ is a substitute for $\operatorname{CCSD}(\mathrm{T})$ in calculations involving openshell species. The ccCA-CC $(2,3)$ method, gives a MAD of $1.7 \mathrm{kcal} / \mathrm{mol}$ relative to experiment for the G2/97 set. For open-shell species and diradicals, which can frequently be problematic for composite methods, the ccCA-CC $(2,3)$ MAD error is only $0.9 \mathrm{kcal} / \mathrm{mol}$ relative to experiment. These results make the new method competitive with the successful and well-established ccCA-S4 approach. Relative to experiment, for open-shell species and diradicals, the ccCA-CC $(2,3)$ method improves on the ccCA-S4 method by a MAD error of $0.6 \mathrm{kcal} / \mathrm{mol}$. This ability to reliably treat open-shell and diradical species manifests itself in the correct resolution by the ccCA-CC $(2,3)$ method of the competing reaction pathways for the pericyclic rearrangement of bicyclo[1.1.0]butane to trans-1,3-butadiene.

Since the ccCA-CC $(2,3)$ method is able to consistently predict the relative energies for systems that contain species of high diradical character, and for potential energy surfaces in which the diradical character changes significantly from structure to structure, it is possible that other composite methods can take advantage of the $\mathrm{CR}-\mathrm{CC}(2,3)$ approach as a viable replacement for the $\operatorname{CCSD}(\mathrm{T})$ method. In particular, composite methods that employ CR-CC $(2,3)$ can potentially treat systems with a more significant MR character, without the need for true MR methods that are computationally demanding and sometimes require difficult choices when determining an active space.

\section{ACKNOWLEDGMENTS}

The calculations were carried out on a cluster of Dell nodes. This research was supported at the Ames Laboratory by the U.S. Department of Energy, Office of Basic Energy Sciences, under Contract No. DE-AC02-07CH11358. A.K.W. acknowledges support from the National Science Foundation (Grant No. CHE-0809762). Additional support by the Chemical Sciences, Geosciences and Biosciences Division, Office of Basic Energy Sciences, Office of Science, U.S. Department of Energy (Grant No. DE-FG02-01ER15228) is acknowledged as well.

${ }^{1}$ L. A. Curtiss, J. E. Carpenter, K. Raghavachari, and J. A. Pople, J. Chem. Phys. 96, 9030 (1992).

${ }^{2}$ M. L. McKee and W. N. Lipscomb, J. Am. Chem. Soc. 103, 4673 (1981).
${ }^{3}$ E. W. Ignacio and H. B. Schlegel, J. Comput. Chem. 12, 751 (1991).

${ }^{4}$ J. A. Pople, M. Head-Gordon, and D. J. Fox, J. Chem. Phys. 90, 5622 (1989).

${ }^{5}$ L. A. Curtiss, K. Raghavachari, G. W. Trucks, and J. A. Pople, J. Chem. Phys. 94, 7221 (1991).

${ }^{6}$ L. A. Curtiss, P. C. Redfern, and K. Raghavachari, J. Chem. Phys. 126, 084108 (2007).

${ }^{7}$ L. A. Curtiss, P. C. Redfern, and K. Raghavachari, J. Chem. Phys. 127, 124105 (2007).

${ }^{8}$ S. Parthiban and J. M. L. Martin, J. Chem. Phys. 114, 6014 (2001).

${ }^{9}$ A. D. Boese, M. Oren, O. Atasoylu, and J. M. L. Martin, J. Chem. Phys. 120, 4129 (2004).

${ }^{10}$ A. Karton, E. Rabinovich, and J. M. L. Martin, J. Chem. Phys. 125, 144108 (2006).

${ }^{11}$ C. F. Melius and M. D. Allendorf, J. Phys. Chem. 104, 2168 (2000).

${ }^{12}$ B. Anantharaman and C. F. Melius, J. Phys. Chem. A 109, 1734 (2005).

${ }^{13}$ G. A. Petersson, A. Bennett, T. G. Tensfeldt, M. A. Al-Laham, W. A. Shirley, and J. Mantzaris, J. Chem. Phys. 89, 2193 (1988).

${ }^{14}$ G. A. Petersson and M. A. Al-Laham, J. Chem. Phys. 94, 6081 (1991).

${ }^{15}$ G. P. F. Wood, L. Radom, G. A. Petersson, E. C. Barnes, M. J. Frisch, and J. J. A. Montgomery, J. Chem. Phys. 125, 094106 (2006).

${ }^{16}$ G. A. Petersson, T. G. Tensfeldt, and J. J. A. Montgomery, J. Chem. Phys. 94, 6091 (1991).

${ }^{17}$ J. J. A. Montgomery, J. W. Ochterski, and G. A. Petersson, J. Chem. Phys. 101, 5900 (1994).

${ }^{18}$ A. Tajti, P. G. Szalay, A. G. Csaszar, M. Kallay, J. Gauss, E. F. Valeev, B. A. Flowers, J. Vazquez, and J. F. Stanton, J. Chem. Phys. 121, 11599 (2004).

${ }^{19}$ Y. J. Bomble, J. Vazquez, M. Kallay, C. Michauk, P. G. Szalay, A. G. Csaszar, J. Gauss, and J. F. Stanton, J. Chem. Phys. 125, 064108 (2006).

${ }^{20}$ M. E. Harding, J. Vazquez, B. Ruscic, A. K. Wilson, J. Gauss, and J. F. Stanton, J. Chem. Phys. 125, 114111 (2008).

${ }^{21}$ D. A. Dixon, D. Feller, and G. Sandrone, J. Phys. Chem. A 103, 4744 (1999).

${ }^{22}$ D. Feller and D. A. Dixon, J. Phys. Chem. A 103, 6413 (1999).

${ }^{23}$ D. Feller and D. A. Dixon, J. Phys. Chem. A 104, 3048 (2000).

${ }^{24}$ D. Feller, D. A. Dixon, and J. S. Francisco, J. Phys. Chem. A 107, 1604 (2003).

${ }^{25}$ D. Feller, K. A. Peterson, W. A. de Jong, and D. A. Dixon, J. Chem. Phys. 118, 3510 (2003).

${ }^{26}$ L. Pollack, T. L. Windus, W. A. de Jong, and D. A. Dixon, J. Phys. Chem. A 109, 6934 (2005).

${ }^{27}$ P. L. Fast, J. Corchado, M. L. Sanchez, and D. G. Truhlar, J. Phys. Chem. A 103, 3139 (1999).

${ }^{28}$ P. L. Fast, J. C. Corchado, M. L. Sanchez, and D. G. Truhlar, J. Phys. Chem. A 103, 5129 (1999).

${ }^{29}$ P. L. Fast and D. G. Truhlar, J. Phys. Chem. A 104, 6111 (2000).

${ }^{30}$ P. L. Fast, N. E. Schultz, and D. G. Truhlar, J. Phys. Chem. A 105, 4143 (2001).

${ }^{31}$ N. J. De Yonker, T. Grimes, S. Yockel, A. A. Dinescu, B. Mintz, A. K. Wilson, and T. R. Cundari, J. Chem. Phys. 125, 104111 (2006).

${ }^{32}$ N. J. De Yonker, T. R. Cundari, and A. K. Wilson, J. Chem. Phys. 124, 114104 (2006).

${ }^{33}$ N. J. De Yonker, B. Mintz, T. R. Cundari, and A. K. Wilson, J. Chem. Theor. Comput. 4, 328 (2008).

${ }^{34}$ N. J. De Yonker, B. R. Wilson, A. W. Pierpont, T. R. Cundari, and A. K. Wilson, Mol. Phys. 107, 1107 (2009).

${ }^{35}$ T. H. Dunning, Jr., J. Chem. Phys. 90, 1007 (1989).

${ }^{36}$ R. A. Kendall, T. H. Dunning, Jr., and R. J. Harrison, J. Chem. Phys. 96, 6796 (1992)

${ }^{37}$ D. E. Woon and T. H. Dunning, Jr., J. Chem. Phys. 98, 1358 (1993).

${ }^{38}$ D. E. Woon and T. H. Dunning, Jr., J. Chem. Phys. 100, 2975 (1994).

${ }^{39}$ K. Raghavachari, G. W. Trucks, J. A. Pople, and M. Head-Gordon, Chem. Phys. Lett. 157, 479 (1989).

${ }^{40}$ T. I. Sølling, D. M. Smith, L. Radom, M. A. Freitag, and M. S. Gordon, J. Chem. Phys. 115, 8758 (2001).

${ }^{41}$ J. M. L. Martin and S. Parthinban, Quantum Mechanical Prediction of Thermochemical Data, edited by J. C. a. A. Szarecka (Kluwar, Dordrecht, The Netherlands, 2001), Vol. 22, p. 31.

${ }^{42}$ B. Mintz, T. G. Williams, L. Howard, and A. K. Wilson, J. Chem. Phys. 130, 234104 (2009).

${ }^{43}$ G. A. Oyedepo, C. Peterson, and A. K. Wilson, J. Chem. Phys. 135, 094103 (2011). 
${ }^{44}$ W. Jiang and A. K. Wilson, J. Chem. Phys. 134, 034101 (2011).

${ }^{45}$ P. Piecuch and M. Wloch, J. Chem. Phys. 123, 224105 (2005).

${ }^{46}$ M. Wloch, J. R. Gour, and P. Piecuch, J. Phys. Chem. A 111, 11359 (2007).

${ }^{47}$ P. Piecuch, S. A. Kucharski, K. Kowalski, and M. Musiał, Comput. Phys. Commun. 149, 71 (2002).

${ }^{48}$ M. W. Schmidt, K. K. Baldridge, J. A. Boatz, S. T. Elbert, M. S. Gordon, J. H. Jensen, S. Koseki, and N. Matsunaga, J. Comput. Chem. 14, 13471363 (1993).

${ }^{49}$ L. A. Curtiss, P. C. Redfern, K. Raghavachari, V. Rassalov, and J. A. Pople, J. Chem. Phys. 110, 4703 (1999).

${ }^{50}$ A. Kinal and P. Piecuch, J. Phys. Chem. A 111, 734 (2007).

${ }^{51}$ C. Moller and M. S. Plesset, Phys. Rev. 46, 618 (1934).

${ }^{52}$ A. D. Becke, J. Chem. Phys. 98, 5648 (1993).

${ }^{53}$ D. E. Woon and T. H. Dunning, Jr., J. Chem. Phys. 103, 4572 (1995).

${ }^{54}$ K. A. Peterson and T. H. Dunning, Jr., J. Chem. Phys. 117, 10548 (2002).

${ }^{55}$ L. A. Curtiss, P. C. Redfern, K. Raghavachari, and J. A. Pople, J. Chem. Phys. 114, 108 (2001).

${ }^{56}$ W. A. de Jong, R. J. Harrison, and D. A. Dixon, J. Chem. Phys. 114, 48 (2001).

${ }^{57}$ M. Douglas and N. M. Kroll, Ann. Phys. 82, 89 (1974).
${ }^{58}$ B. A. Hess, Phys. Rev. A 33, 3742 (1986).

${ }^{59}$ S. Yockel and A. K. Wilson, Theor. Chem. Acc. 120, 119 (2008).

${ }^{60}$ S. F. Boys, Proc. R. Soc. London A, Ser. A 200, 542 (1950).

${ }^{61} \mathrm{~F}$. Jensen, Introduction to Computational Chemistry, 2nd ed. (Wiley, Odense, 2007).

${ }^{62}$ L. A. Curtiss, K. Raghavachari, P. C. Redfern, and J. A. Pople, J. Chem. Phys. 106, 1063 (1997).

${ }^{63}$ A. Karton and J. M. L. Martin, J. Phys. Chem. A 111, 5936 (2007).

${ }^{64}$ NIST Standard Reference Database 101, 2011.

${ }^{65}$ K. B. Wiberg and J. M. Lavanish, J. Am. Chem. Soc. 88, 5272 (1966).

${ }^{66}$ G. L. Closs and P. E. Pfeffer, J. Am. Chem. Soc. 90, 2452 (1968).

${ }^{67}$ K. A. Nguyen and M. S. Gordon, J. Am. Chem. Soc. 117, 3835 (1995).

${ }^{68}$ J. J. Lutz and P. Piecuch, J. Chem. Phys. 128, 154116 (2008).

${ }^{69}$ D. A. Mazziotti, J. Phys. Chem. A 112, 13684 (2008).

${ }^{70}$ R. Berner and A. Lüchow, J. Phys. Chem. A 114, 13222 (2010).

${ }^{71}$ M. Schmidt and M. S. Gordon, Annu. Rev. Phys. Chem. 49, 233 (1998)

${ }^{72}$ B. O. Roos, Advances in Chemical Physics, edited by K. P. Lawley (Wiley Interscience, New York, 1987), Vol. 69, p. 339.

${ }^{73}$ R. Srinivasan, A. Levi, and I. Haller, J. Phys. Chem. 58, 1775 (1965).

${ }^{74}$ K. B. Wiberg and R. A. Fenoglio, J. Am. Chem. Soc. 90, 3395 (1968). 